\title{
The Role of Mining Intensity and Pre-existing Fracture Attributes on Spatial, Temporal and Magnitude Characteristics of Microseismicity in Longwall Coal Mining
}

\author{
Wenzhuo Cao ${ }^{1}$ (1) $\cdot$ Sevket Durucan ${ }^{1} \cdot$ Wu Cai $^{1,2} \cdot \mathrm{Ji}^{-Q^{-}}$uan Shi ${ }^{1} \cdot$ Anna Korre $^{1} \cdot$ Sergej Jamnikar $^{3} \cdot$ Janez Rošer $^{3}$. \\ Adam Lurka ${ }^{4} \cdot$ Robert Siata ${ }^{4}$
}

Received: 2 August 2019 / Accepted: 22 May 2020 / Published online: 31 May 2020

(c) The Author(s) 2020

\begin{abstract}
Knowledge regarding microseismic characteristics associated with longwall coal mining is crucial in evaluating the potential for underground mining hazards. Although microseismicity is induced by mining activities, it still remains uncertain as to what extent mining activities influence the spatial, temporal, and magnitude characteristics of microseismicity. To establish a thorough understanding of the relationship between microseismic characteristics and mining activities, a 27-month long microseismic monitoring campaign was conducted around a highly stressed coal zone and eight producing longwall panels at Coal Mine Velenje in Slovenia. Each microseismic event was classified to be associated with the producing longwall panel that triggered it, and the microseismic response to multi-panel longwall top coal caving face advance was analysed. Monitoring data have shown that locations of microseismic events coincided with stress concentrated regions. It was established that both seismic count and energy-intensive regions associated with coal mining in different panels are spatially connected, but they do not fully overlap with mined-out or stress concentrated areas. In addition, microseismic event counts frequency was found to be well correlated with mining intensity, while seismic energy magnitude and spatial distribution are poorly correlated with the same. Therefore, microseismic characteristics could not be explained solely by the mining-induced stress transfer and mining intensity, but are believed to be dominated by pre-existing natural fractures throughout the coal seam. Analyses of these observations helped the development of a conceptual seismic-generation model, which provides new insights into the causes of microseismicity in coal mining.
\end{abstract}

Keywords Mining-induced microseismicity $\cdot$ Longwall top coal caving mining $\cdot$ Natural fractures $\cdot$ Stress concentration . In-situ measurements

\section{Introduction}

Underground coal mining is faced with adverse stress and gas emission environments, and hazards such as rock bursts and coal and gas outbursts have long been a serious risk to

Wenzhuo Cao

w.cao15@imperial.ac.uk

1 Department of Earth Science and Engineering, Royal School of Mines, Imperial College London, London SW7 2AZ, UK

2 School of Mines, China University of Mining and Technology, Xuzhou 221116, Jiangsu, China

3 Coal Mine Velenje, Partizanska 78, Velenje, Slovenia

4 Glowny Instytut Gornictwa, Plac Gwarkow 1, Katowice 40-166, Poland the safety of personnel and equipment. These hazards have become more acute as deeper and deeper coal seams are being mined. The microseismic monitoring technique has been utilised as a tool to identify the regions prone to coal and gas outbursts from the late 1930s and early 1940s (Jackson 1984).

Mining-induced microseismicity is conventionally considered to be caused by fracturing of intact rock as a result of the sudden release of accumulated strain energy around underground openings. The occurrence and distribution of seismicity are affected by a combination of exploitationinduced, tectonic and coseismic stresses (Sato and Fujii 1988; Fritschen 2010; Kozłowska et al. 2016). Coal extraction usually has the most pronounced effect on the stress environment. As such, induced microseismic characteristics are closely correlated with mining activity in temporal and 
spatial sequences. Furthermore, it has been reported that microseismic events tend to cluster at a location close to the mining openings (Woodward et al. 2018). During longwall coal mining, it has been found that the majority of seismic sources occurred at a distance ranging from $10-80 \mathrm{~m}$ to 100-200 $\mathrm{m}$ in front of a longwall face (Jackson 1984; Lasocki 1993; Yu et al. 2017). The microseismic events recorded at Coal Mine Velenje correlated spatially with the face advance (Si et al. 2015). An apparent time dependency of monitored microseismic signals was observed at different excavation rounds (Young et al. 2005). The majority of the seismic events took place within the first $24 \mathrm{~h}$ after an excavation, although a few events happened up to 10 days later.

Underground mining hazards which are triggered by exploitation-induced stress perturbations also display spatial and temporal correlation with microseismic events. Field observations of rock bursts phenomena in Polish coal mines suggested that the destruction in operating workings usually occurred when hypocentres of seismic events were located near the damaged workings and seismic energy was higher than $1 \times 10^{5} \mathrm{~J}$ (local magnitude, $M_{\mathrm{L}}>1.7$ ) (Mutke 2008). It is common that microseismic event rates intensify steadily during several days before an outburst, and begin to decrease immediately prior to rock failure (McKavanagh and Enever 1980; Shen et al. 2008).

However, the stress-dominant (intact) rock fracturing mechanism for the generation of microseismicity cannot satisfactorily explain the following field observations: (1) source-scaling property of microseismicity; and (2) microseismicity locates mainly in the far-field of excavation. Discrete natural fractures have been recognised to play an important role in the geomechanical and hydrological behaviour of underground rocks (Zimmerman and Main 2003; Lei et al. 2017). Extensive research reported that fluid injectioninduced seismicity in geological $\mathrm{CO}_{2}$ sequestration (Rutqvist et al. 2016), hydraulic fracturing of the unconventional reservoir (Zhai and Shirzaei 2018), enhanced geothermal system (Staszek et al. 2017) and disposal of wastewater (Shah and Keller 2017) is attributed to the reactivation of natural fractures widely distributed in the upper crust by overpressures. Likewise, mine-induced microseismicity is in essence the slippage of pre-existing subsurface fractures triggered by mining activities. Recent publications confirmed that hypocentres of mining-induced microseismicity are bound to preexisting subsurface structures such as faults or fracture-rich regions (Hassani et al. 2018; Ma et al. 2018a). Therefore, the role of natural fractures throughout the active mining region needs to be highlighted in the explanation of microseismic response to coal extraction.

Previous research by the authors (Cao et al. 2018, 2019) developed a microseismicity modelling methodology based upon the premise that microseismicity is triggered due to the interplay of mining-induced stress and the pre-existing fracture field throughout the coal seam and surrounding rock masses during longwall mining. The modelling methodology combines deterministic stress and failure analysis of the coal seam with slip evaluation of stochastically distributed pre-existing fractures. The developed modelling approach has been successfully applied to the analysis of the recorded seismic energy around a longwall top coal caving (LTCC) panel at Coal Mine Velenje over a period of 8 weeks.

In a more recent study, microseismic data recorded around a highly stressed central coal pillar and eight surrounding LTCC mining panels at Coal Mine Velenje were analysed in conjunction with the respective face advance records of these panels over a 27-month period. In particular, the role of stress concentration, mining intensity and fracture field in contributing to microseismicity was investigated to determine which factors dominate spatial, temporal and magnitude characteristics of microseismicity. Based on the improved understanding of the fracture-slip seismic-generation mechanism, a conceptual model was developed to interpret field microseismic observations and provide new insights into the causes of microseismicity in coal mining.

\section{Coal Mine Velenje}

Located in North East Slovenia, Coal Mine Velenje currently produces around 3.4 million tonnes of lignite per annum from a coal basin lying in a synclinal valley (Fig. 1). The coal deposit is lens-shaped, extending to a length of $8.3 \mathrm{~km}$ in the WNW-ESE direction and having a width between 1.5 and $2.5 \mathrm{~km}$. The coal seam is $165 \mathrm{~m}$ thick in the central part and pinches out towards the margins. Depth of the lignite seam varies from 200 to $500 \mathrm{~m}$ with low quality minor outcrops on eastern border of the seam. The coal produced is used by the neighbouring Šoštanj power station.

The Velenje lignite was formed within a synclinal basin formed in the Pliocene era in between two major faults: the Šoštanj and Smrekovec (Fig. 2) as a result of polyphase dextral strike-slip faulting at the junction of three tectonic units-the Central Karavanke Mountains, the Southern Karavanke Mountains and the Gorenje-Šoštanj block. The coal basin was filled during Pliocene and Plio-Pleistocene times by a thick succession of heterogeneous clastic sediments $(1000 \mathrm{~m}<)$. The Velenje lignite seam is embedded approximately in the middle of the succession. The bedding planes of coal are nearly horizontal or slightly inclined (Markič and Sachsenhofer 2010).

More than 160 surface exploration bore-holes have been drilled in the area of the coal seam to characterise the overburden and the lignite seam. Besides surface drilling, continuous in-mine drilling is used to prove local geology of the seam and surrounding rocks, especially aquifers. The border between the seam and roof strata is clean and consists 


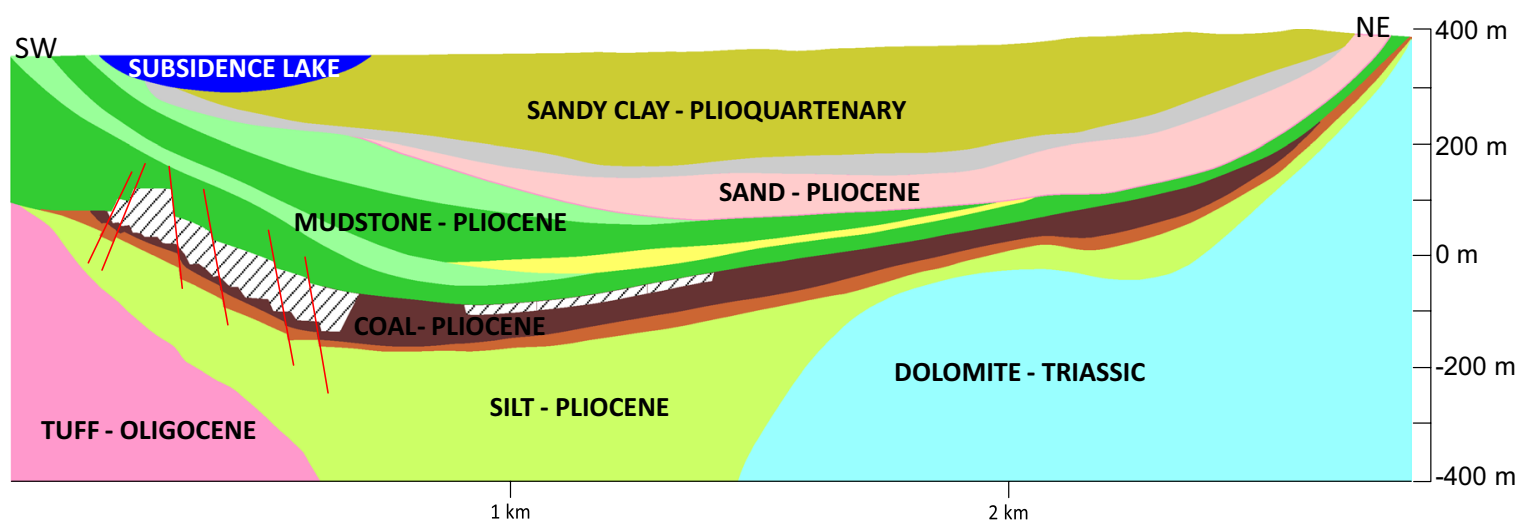

Fig. 1 Schematic SW-NE trending geological cross-section of the Velenje lignite deposit (after Markič and Sachsenhofer 2010)

Fig. 2 Geological composition of Velenje basin and surroundings (after Brezigar 1986)

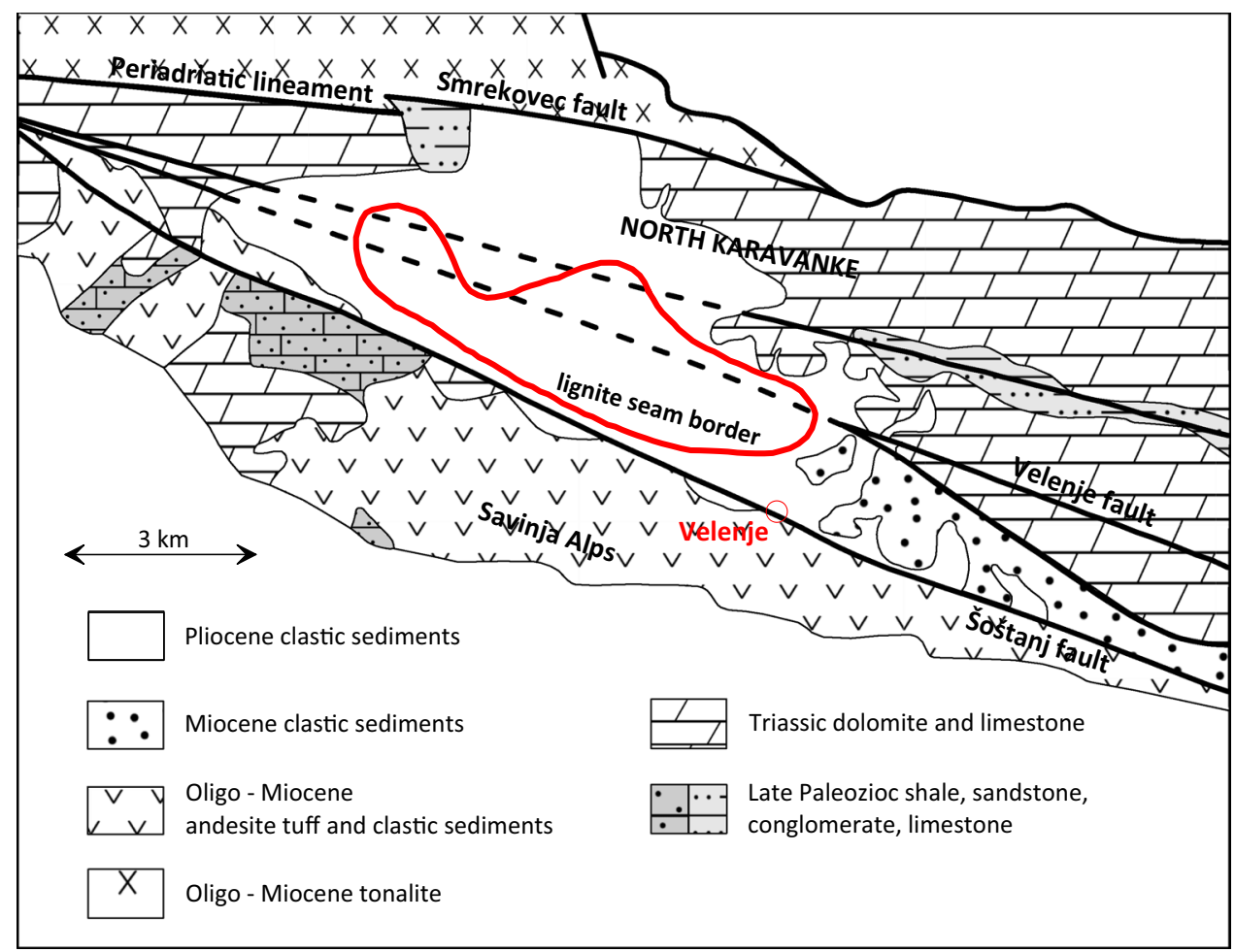

The mining method practiced at the mine is a combination of multi-level mining and longwall top coal caving (LTCC), developed and optimised over the decades as the most effective method due to extreme seam thickness, depth and prevailing geotechnical conditions (Fig. 3) (Jeromel et al. 2010; Si et al. 2015). From the top to the bottom, the entire coal deposit is divided into a series of mining levels ranging from 10 to $20 \mathrm{~m}$ thick, mined in time-sequence with at least 6 months between the mining of each underlying longwall panel. At each level, the lower part of the seam, which is 3-4 m high, is cut by a shearer under the hydraulic supports while the upper section is allowed to cave and be collected at the face. Unlike most than a xylite-rich area. 


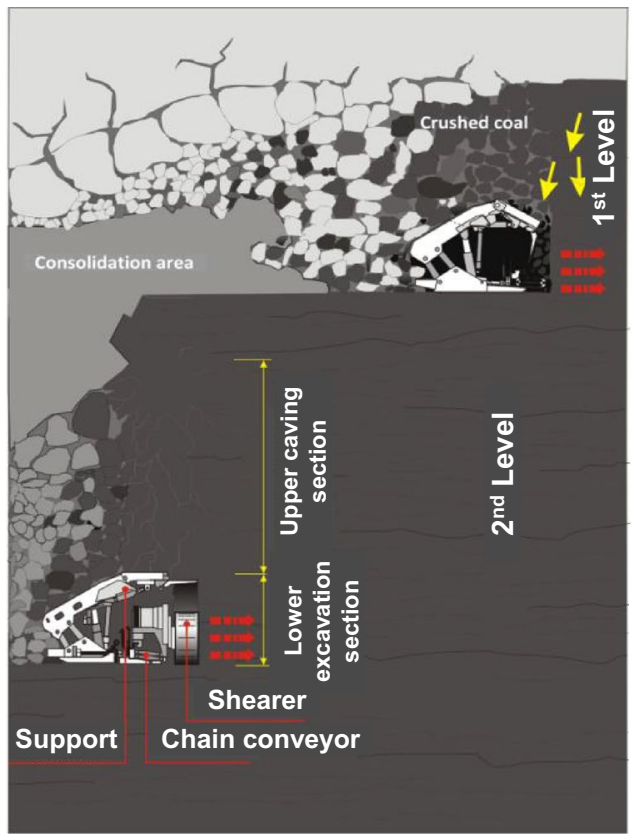

(a)

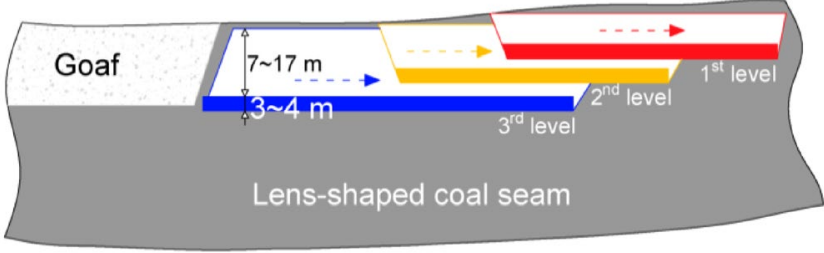

(b)

Fig. 3 a Schematic of the multi-level longwall top coal caving mining method implemented at the ultra-thick coal deposit of Coal Mine Velenje (after Jeromel et al. 2010), and b schematic of the multi-level longwall layout

LTCC applications where the caved top coal is loaded from behind the hydraulic supports, the top coal is caved and recovered in front of the supports at Coal Mine Velenje. A more detailed account of the Velenje Mining Method can be found in Likar et al. (2012) and Si et al. (2015).

Continued coal production in the mine over the last century has caused the central coal pillar, which protects the main mine infrastructure in the production districts, to be highly stressed. As shown in Fig. 4, the central coal pillar is surrounded by a number of longwall panels which are extracted in succession based on the mine plan. This highstress concentration has increased the risk of rockburst and coal and gas outburst considerably during the development and mining of these panels in recent years. Longwall coal production at $-80 \mathrm{~m}$ level started in 2015 , and gradually transferred to below - 95 m level from 2017 . Nine longwall panels have been in production sequentially during 2016-2019. Longwall panels K.-80/B, K.-80/C, K. $-80 / \mathrm{D}, \mathrm{K} .-80 / \mathrm{E}$, and CD2 monitored in this study were at $-80 \mathrm{~m}$ level, with the other four panels (K.-95/A, K.-95D, K.-95/E and CD3G) operating at - $95 \mathrm{~m} \mathrm{level.}$ Longwall panels K.-80/B, K.-80/C, K.-80/D, K.-80/E, K.-95/A and K.-95/E retreated in the southwest direction towards the central coal pillar, whereas panels CD2 and CD3G advanced away from the central coal pillar, at an angle of about $120^{\circ}$ to the other panels. Aiming to reduce the impact of stress concentration on the main mine infrastructure in the central coal pillar, the production height of two panels (K.-95/E and CD3G) was limited to $5 \mathrm{~m}$ and $9 \mathrm{~m}$, respectively.

To maintain production targets, coal was mined concurrently from two longwall panels, which were normally separated spatially to spread out stress concentration around the mined-out areas. However, due to ventilation and coal transportation constraints, two neighbouring panels (K.-80/D and K. $-80 / C$ ) were in production at the same time for a short period between January and March 2017. There were also periods when three longwall panels were being mined (August-October 2016 and January-March 2017), as well as with only one longwall panel in operation (June-August 2016). The production sequence for eight of the nine longwall panels are summarised in Table 1. Coal production at longwall panel K.-95/D had only started at the time of writing this paper, therefore, the microseismic monitoring data from this panel are not included here.

The mine normally works 5 days per week, and three 8-h shifts per day. The average face advance rate for the panels was approximately 10-20 m per week, yielding a daily coal production of 4000-9000 tonnes. 
Fig. 4 Mine production layout at -80 and $-95 \mathrm{~m}$ production levels during 2016-2019 and the distribution of installed seismic stations of the microseismic monitoring system at Coal Mine Velenje. The grey zone indicates the approximate shape of the central coal pillar protecting the main mine infrastructure in the production district

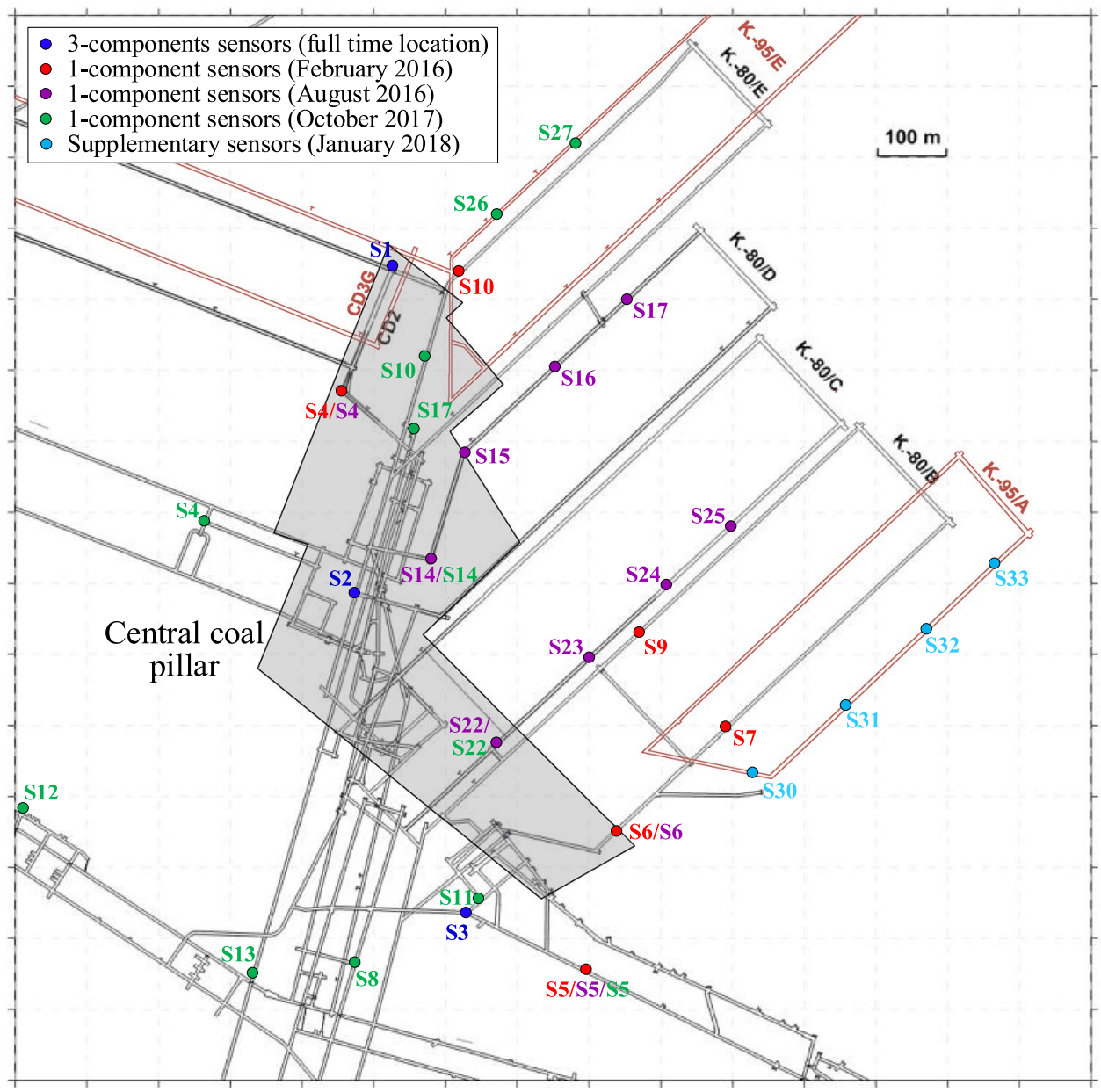

Table 1 Longwall panel production sequence and the associated recorded microseismicity during the monitoring period (29/02/201620/05/2018) at Coal Mine Velenje

\begin{tabular}{llllc}
\hline Panel name & Start date & $\begin{array}{l}\text { Completion } \\
\text { date }\end{array}$ & $\begin{array}{l}\text { Cumulative } \\
\text { face advance } \\
(\mathrm{m})\end{array}$ & Event counts \\
\hline K.-80/B & $11 / 10 / 2015$ & $19 / 10 / 2016$ & 539.9 & $5084^{*}$ \\
K.-80/E & $15 / 10 / 2015$ & $06 / 06 / 2016$ & 647.5 & $261^{*}$ \\
CD2 & $12 / 08 / 2016$ & $12 / 07 / 2017$ & 441.0 & 1157 \\
K.-80/D & $16 / 08 / 2016$ & $28 / 02 / 2017$ & 632.8 & 2736 \\
K.-80/C & $19 / 01 / 2017$ & $05 / 02 / 2018$ & 654.4 & 6803 \\
K.-95/E & $11 / 07 / 2017$ & $15 / 03 / 2018$ & 635.2 & 502 \\
K.-95/A & $12 / 02 / 2018$ & - & 166.1 & 49 \\
CD3G & $26 / 03 / 2018$ & - & 114.2 & 510 \\
\hline
\end{tabular}

*Number of microseismic events for K.-80/B and K.-80/E panels was counted from 29/02/2016 onwards

\section{In Situ Microseismic Monitoring at Coal Mine Velenje}

A 32-channel flameproof automated seismic observation system (SOS) developed by the Laboratory of Mining Geophysics of Central Mining Institute (GIG) in Poland was used for the underground microseismic monitoring at Coal Mine Velenje. A detailed description of the system configuration, installation of geophones, and data acquisition and processing procedure can be found in Si et al. (2015).

The installed microseismic monitoring system encompassed the eight LTCC panels in production around the central coal pillar at the time. The number and locations of seismic sensors were determined on the basis that the investigated area should be surrounded by seismic sensors. Although attempts have been made to achieve full coverage of the investigation area, panels CD2, CD3G, and K.-95/E were not fully covered due to technical limits such as access to longwall panels and gate roads, available cable lines and seismic sensors, and noise levels. At the start of the seismic monitoring campaign in February 2016, 3 triaxial seismic sensors and 6 uniaxial seismic sensors were installed to surround the then active 
longwall panels K.-80/B and K.-80/E. As mining progressed and new longwall faces came into production, the number of uniaxial seismic sensors in the SOS system was increased to 11 (from August 2016) and then 12 (from October 2017) later on (Fig. 4) to surround a larger area disturbed by longwall mining. An additional set of 4 uniaxial seismic sensors were installed at - $95 \mathrm{~m}$ level in January 2018.

The seismic sensors should ideally be placed in a non-planar array. Practical ways to construct a 3D monitoring sensor network include arranging seismic sensors in roadways at different production levels, and embedding seismic sensors through directional deep holes. However, there was limited access to the mined out and caved/abandoned levels at the mine, and it was difficult to maintain cables connected to sensors over the microseismic monitoring period when mine production and roadway development were underway in a lower level. Therefore, the geophones were installed only at the production levels at any one time, which meant that the vertical coverage of the seismic sensor network was limited and only microseismic activities that occurred close to the two production levels studied were accurately identified. The triaxial seismic sensors installed at the permanent roadways remained there throughout the whole period of the project, whereas other sensors were relocated to the new longwall panel gate roads according to technical and mining conditions. As longwall mining was completed at $-80 \mathrm{~m}$ level panels during the monitoring period, seismic sensors were gradually moved to active panels K.-95/E and K.-95/A in the lower production level.

First arrival and end times of seismic $\mathrm{P}$ and $\mathrm{S}$ waves from each receiving geophone (channel) are required to determine the location and timing of a seismic event. In this study, those times were picked manually to achieve high accuracy. Figure 5 illustrates an example of picked arrival times for recorded $\mathrm{P}$ and $\mathrm{S}$ waves in different geophones.

As most microseismic hypocentres are relatively close to the seismic sensors, the attenuation of energy released from microseismic events at Coal Mine Velenje was assumed to be less than $10 \%$. The energy radiated from each microseismic event was calculated on the basis of time-integrated values of particle vibration velocities of $\mathrm{P}$ and $\mathrm{S}$ waves, $\dot{u}_{P}(t)$ and $\dot{u}_{S}(t)$ respectively (Shearer 1975):

$E_{r}=4 \pi \rho v_{P} r^{2} \frac{<U_{P m}^{2}>}{U_{P}^{2}} \int_{t_{1}}^{t_{2}}\left|\dot{u}_{P}(t)\right|^{2} d t+4 \pi \rho v_{S} r^{2} \frac{<U_{S m}^{2}>}{U_{S}^{2}} \int_{t_{1}}^{t_{2}}\left|\dot{u}_{S}(t)\right|^{2} d t$

Fig. 5 An example of recorded raw microseismic signals and the pick up of arrival times for $\mathrm{P}$ and $\mathrm{S}$ waves (the seismic event occurred at 19:35:23 on $26 / 09 / 2016$, with a seismic energy of $104 \mathrm{~J}$ )

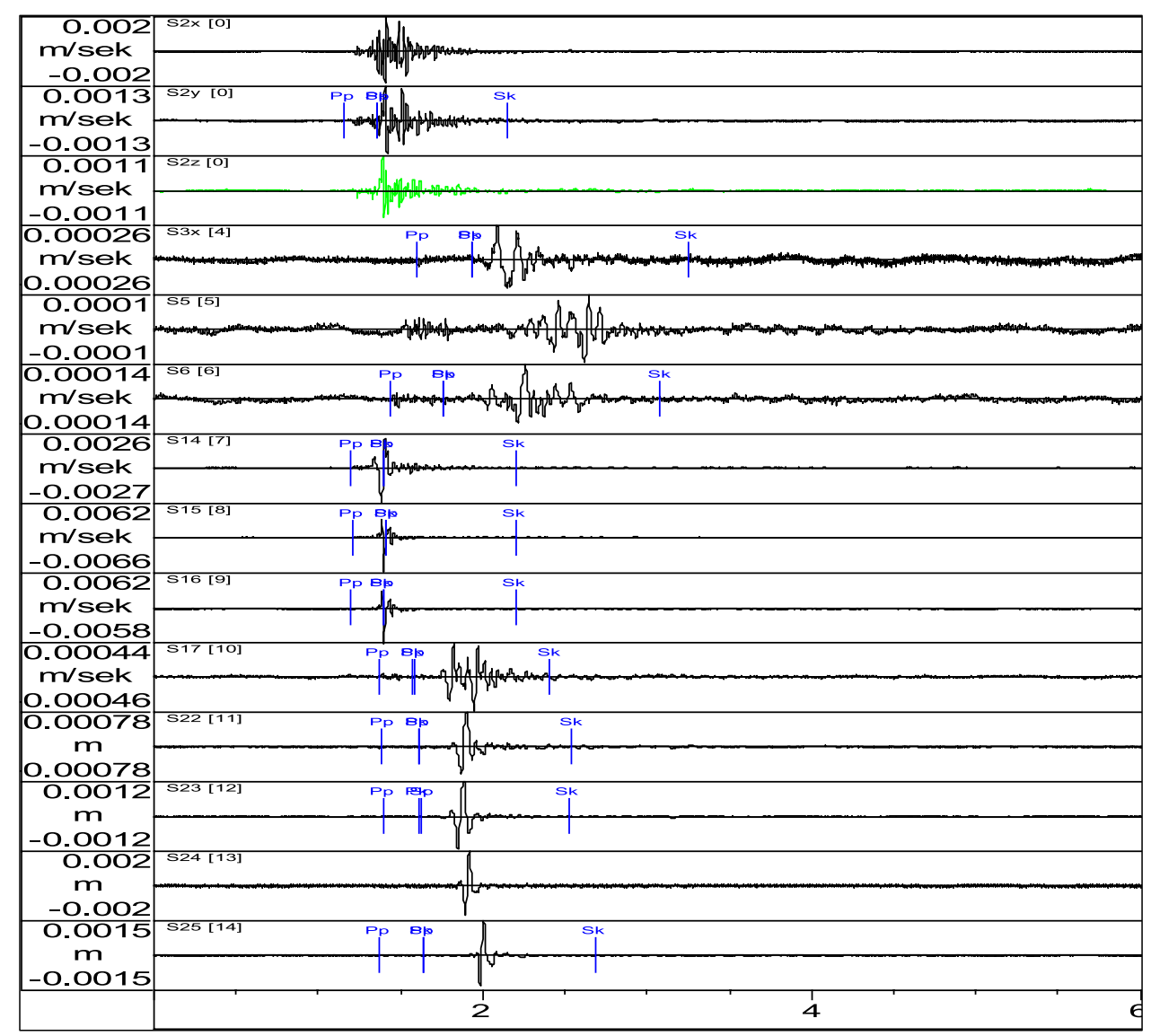


where $r$ is the distance between the source and receiver, $\rho$ is the density of medium, $v_{\mathrm{P}}$ and $v_{\mathrm{S}}$ are $\mathrm{P}$ and $\mathrm{S}$ wave velocities travelling through the medium, $U_{\mathrm{P}}^{2}$ and $U_{\mathrm{S}}^{2}$ are the radiation pattern terms, $<U_{\mathrm{Pm}}^{2}>$ and $<U_{\mathrm{Sm}}^{2}>$ are the mean values over the local sphere of $U_{\mathrm{P}}^{2}$ and $U_{\mathrm{S}}^{2}$ for $\mathrm{P}$ and $\mathrm{S}$ waves, and $t_{1}$ and $t_{2}$ are times bounding a group of $\mathrm{P}$ and $\mathrm{S}$ waves. The minimum accurate detectable energy level of the SOS microseismic monitoring system is around $10^{2} \mathrm{~J}$.

\section{Analysis of Field Recorded Microseismicity}

During the monitoring period between 29 February 2016 and 20 May 2018, a total of over 17,000 microseismic events were identified around the eight LTCC panels at the two mining levels. The complete record of the daily face advance at each LTCC panel was also available, which allowed the recorded microseismicity to be correlated with the prevailing face-line positions.

To facilitate the analysis, each microseismic event was associated with one of the eight panels, which is active and whose working face-line position is located closest to the event. Here, a longwall panel is considered to remain active until 7 days after the coal production is completed. It has been recognised that it usually takes a period of time for the stress fields disturbed by longwall mining to reach a new state of equilibrium (Styles et al. 1988). Indeed, a few microseismic events were recorded at weekends when there was no active mining.

Overall, this grouping of the microseismic events has proved to be largely effective since (1) mining-induced stress redistribution usually affects a limited area around LTCC panels; and (2) most simultaneously active LTCC panels were not immediately adjacent to each other over the monitoring period. In some occasions, mining-induced stress disturbance may trigger microseismicity in coals at a distance from the working LTCC panel, but are under critical stress state. In this case, the induced microseismicity is also considered to be associated with the working LTCC panel. It is recognised that microseismicity might also be triggered by a roof collapse in the goaf area or roadway development in the coal mine, rather than by coal excavation at a particular longwall panel. The resulting mis-association is believed to constitute only a small fraction of the whole datasets, considering the limited disturbed areas compared to the LTCC panels. Microseismic event counts associated with each panel are presented in Table 1.

Microseismic events at six completed LTCC panels (K.80/B, K.-80/E, CD2, K.-80/D, K.-80/C and K.-95/E) were analysed for each production week throughout the lifetime of each LTCC panel as presented in the following sections. Longwall mining at panels K.-95/A and CD3G was still underway after 20/05/2018, therefore, microseismicity associated with these panels is not discussed here.

\subsection{Spatial Distribution of Recorded Microseismicity and Its Energy}

The spatial distribution of recorded microseismic events at the starting and ending weeks for each panel are presented in Fig. 6 to illustrate the correlation of mining production and the induced microseismicity. Based on the daily face advance records, the face-line positions of longwall panels (on the first day of each week referred to on these figures) at the same production level are also presented. The active longwall panels serve as the sources of dynamic mining disturbances, while the inactive longwall panels indicate areas of possible large stress concentration.

As illustrated in Fig. 3, microseismicity was clustered around the active longwall panels but was relatively scattered with respect to the working (producing) face-line positions most of the time. When a longwall panel was in operation, the induced microseismicity was located either ahead of or behind the face-line, due to the frequent mining-induced stress movement and adjustment with the face advance. It was noted that microseismicity also occurred close to the abandoned inactive longwall faces for some time after abandonment. In this case, microseismicity tended to occur primarily in front of the inactive face-line. This is because the stress behind the face-line stabilised as the caved roof gradually hardened, while the relatively intact coal (the barrier pillar) in front of the face-line took most of the vertical stress, as well as being subjected to continuous mining disturbances from other longwall panels. Overall, the spatial distribution of microseismicity, specifically its location with respective to longwall faces, was found to be panelspecific. There was a large variation in the magnitude of seismic energy released from different LTCC panels, albeit under similar mining conditions. This indicates significant heterogeneity in the attributes of pre-existing natural fractures in the coal seam.

Figure 7 presents the mined-out area and distribution of the associated microseismic events for each panel throughout the monitoring period. The majority of microseismicity is located within and close to the mined area, as illustrated in Fig. 6. Based on historical data and experience with structural damage caused due to previous seismic events, a kidney-shaped area, where the density of the seismic events has been relatively higher, was identified by the engineers at Coal Mine Velenje. A large part of this area is seen to overlap with the central coal pillar, indicating elevated stress concentration. The spatial location and extent of this area has been undergoing continuous changes with the advance of the longwall faces and is subject to further variation. Furthermore, microseismic events occurred more frequently 


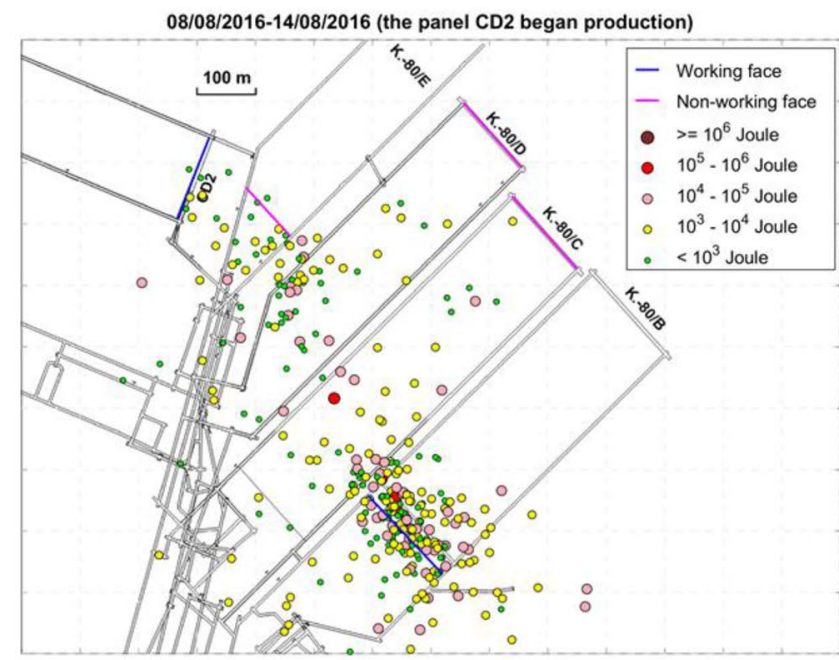

(a)

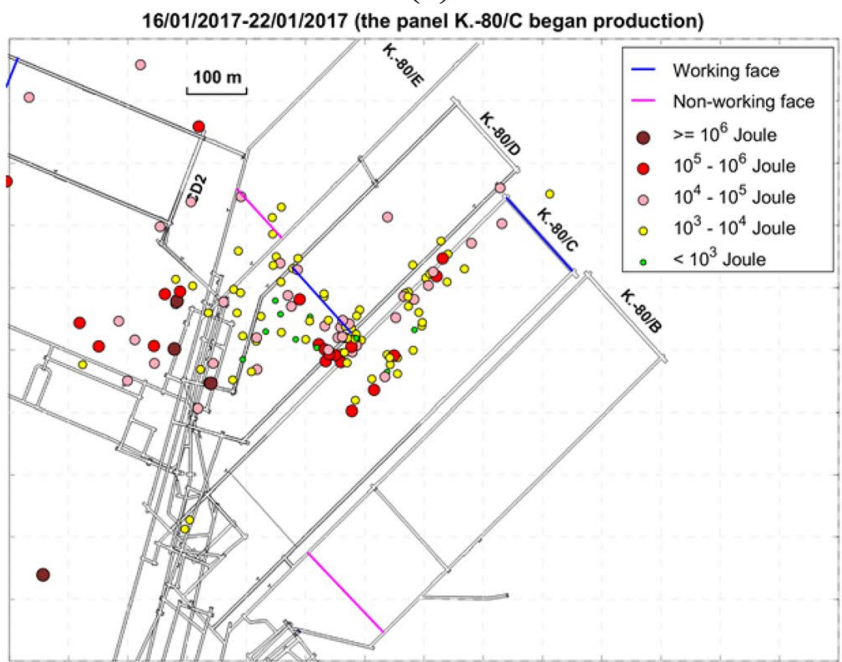

(c)

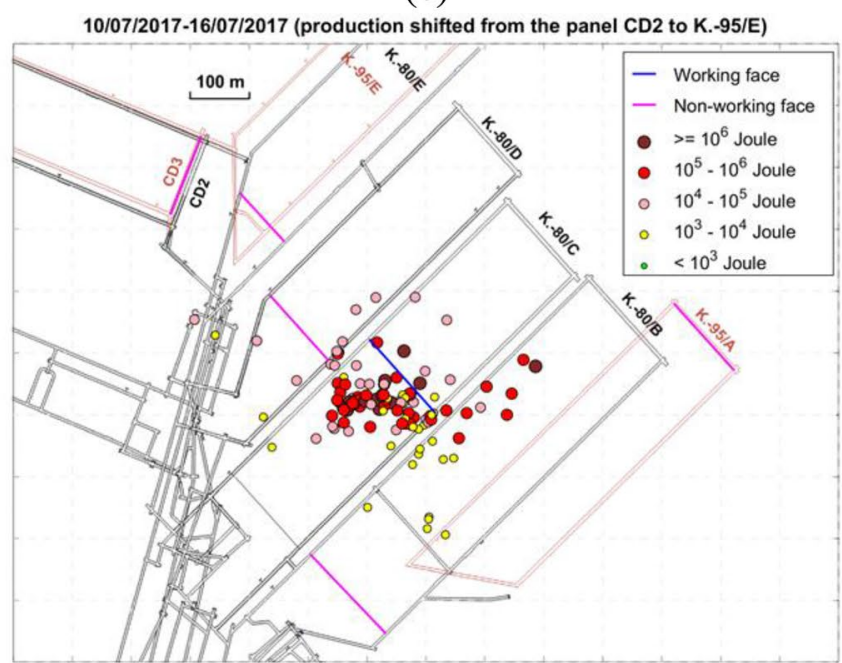

(e)

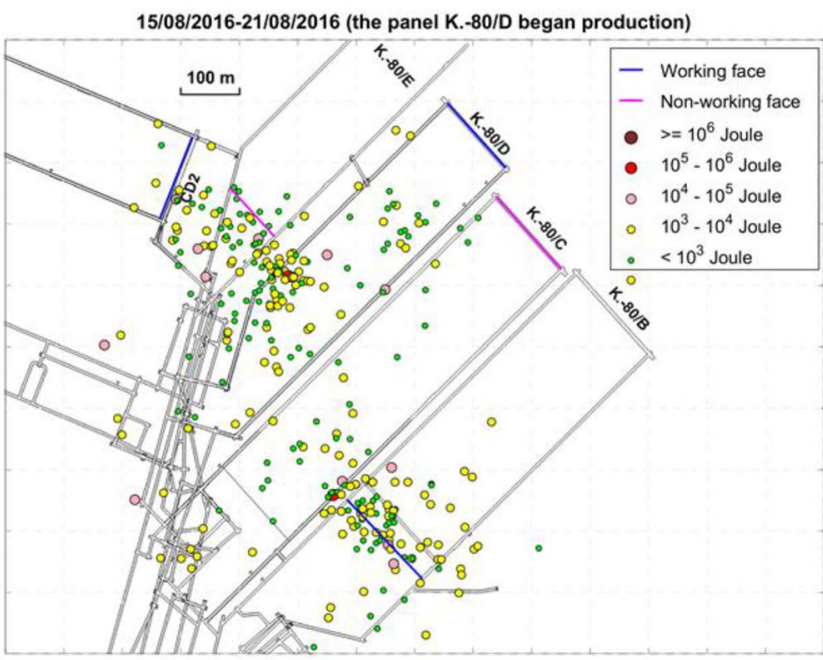

(b)

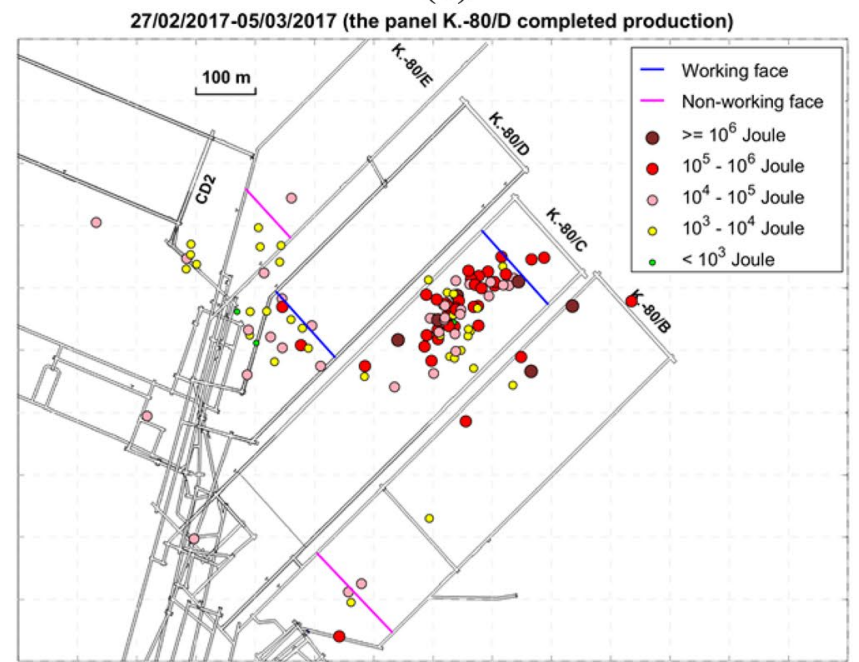

(d)

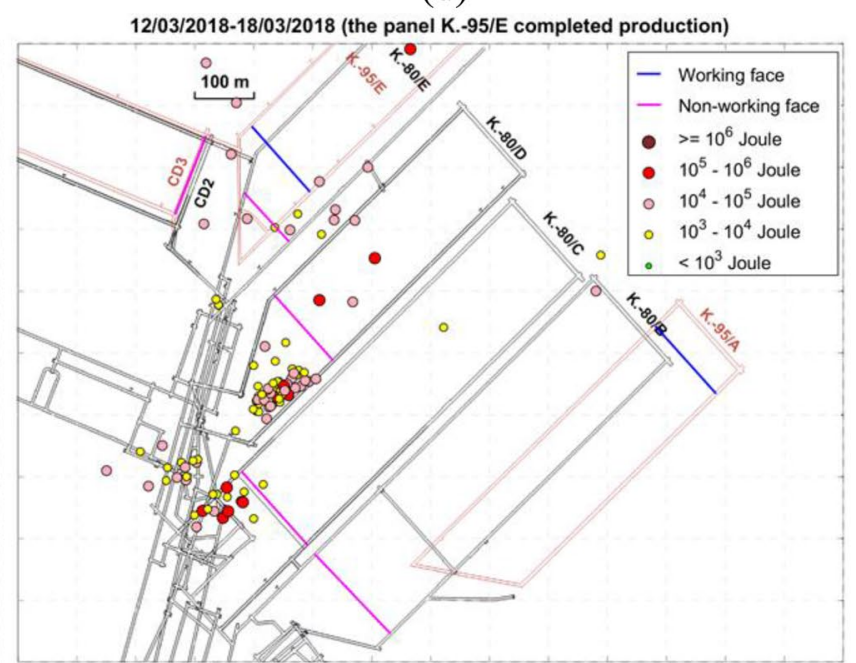

(f)

Fig. 6 Examples of spatial distribution of weekly recorded microseismic events around six longwall panels at Coal Mine Velenje 


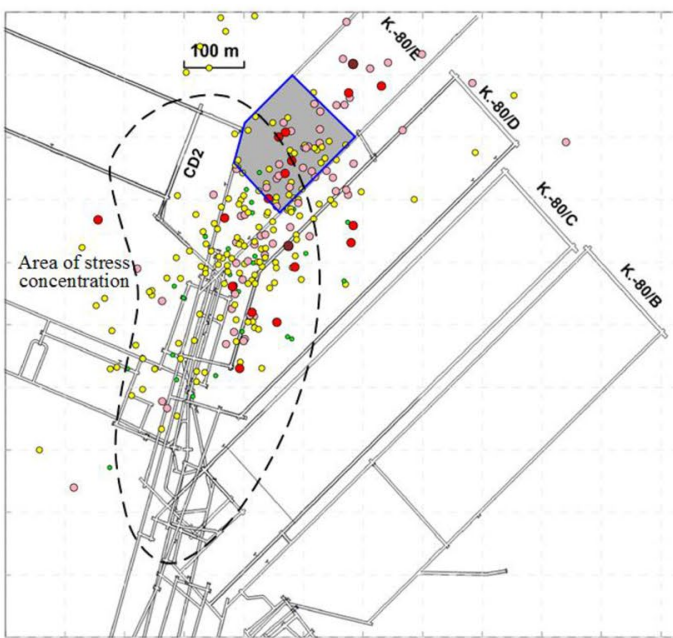

(a)

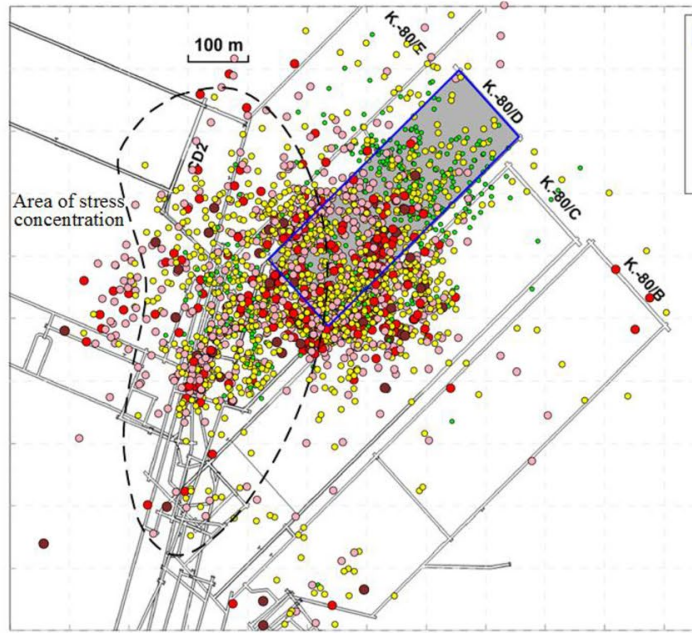

(c)

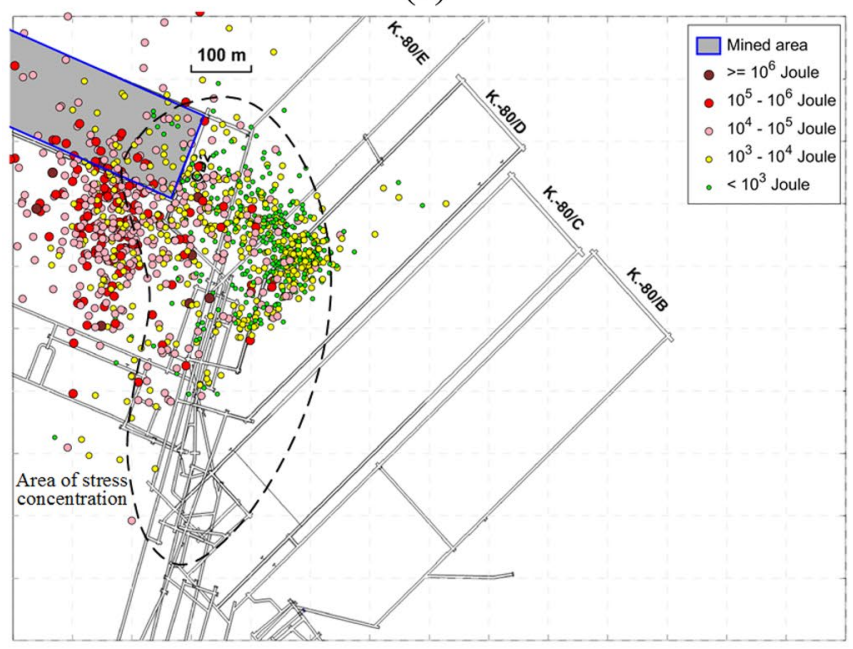

(e)

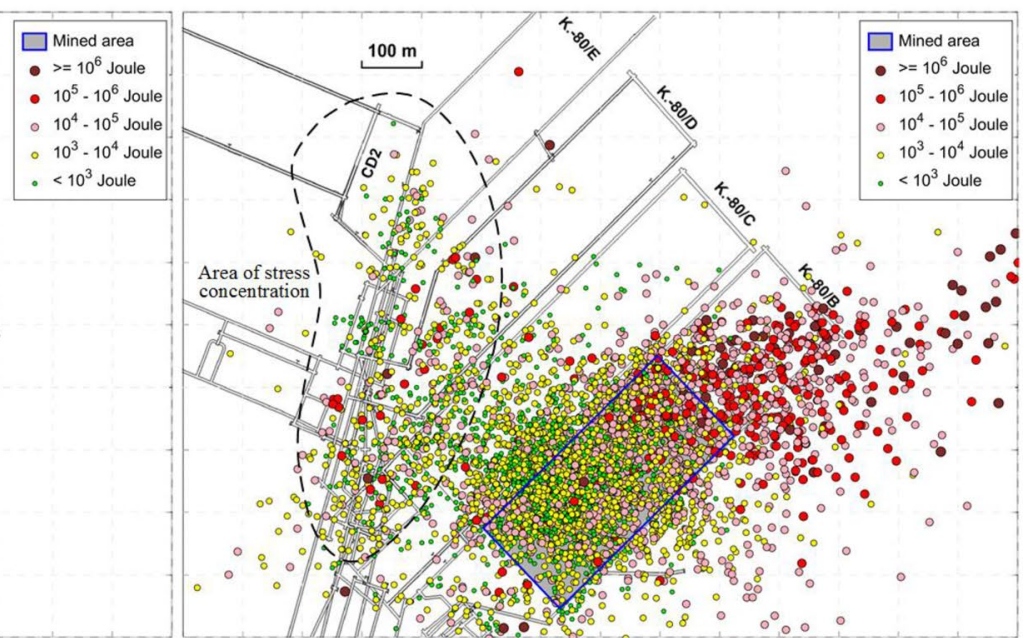

(b)

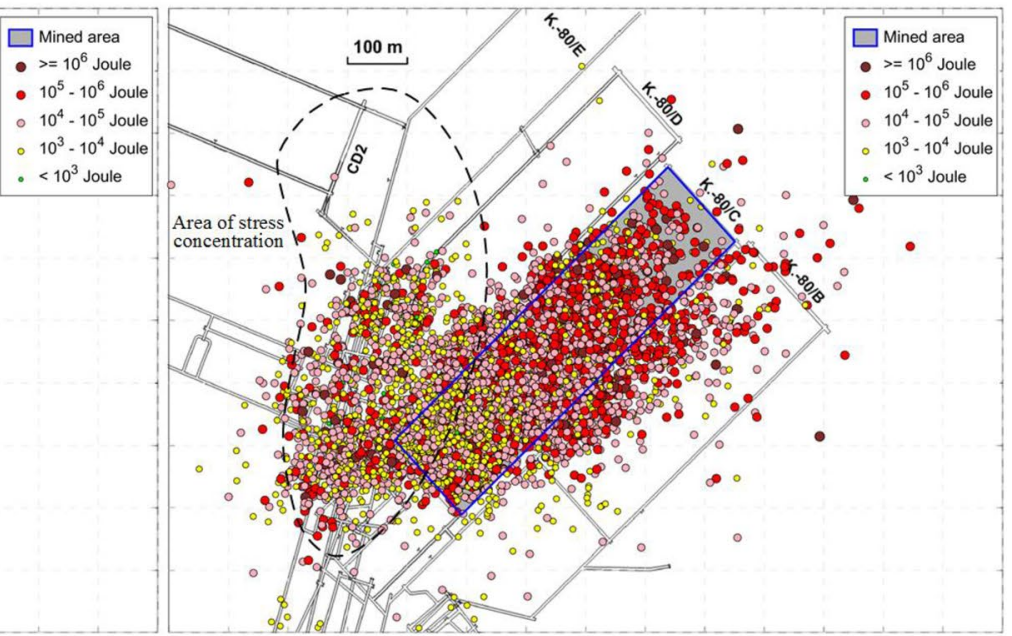

(d)

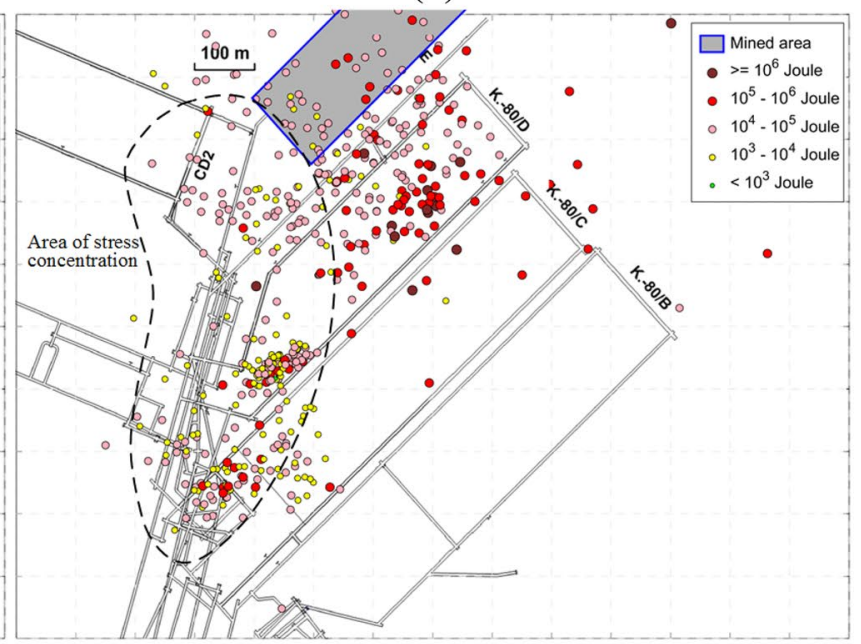

(f)

Fig. 7 Spatial distribution of microseismicity associated with: a panel K.-80/E, b panel K.-80/B, c panel K.-80/D, d panel K.-80/C, e panel CD2, and $\mathbf{f}$ panel K.-95/E throughout the monitoring period 
around gate roads in the vicinity of the central coal pillar, when hydraulic supports are removed during the abandonment of longwall panels.

Microseismic events close in space tended to have similar energy levels, regardless of the time of occurrence, an indication of spatial continuity of the fracture attributes. For example, microseismicity induced by LTCC mining in the East, Northeast, and partly in the Northwest of the study region, had an energy release greater than $10^{4} \mathrm{~J}$, while the North of the kidney-shaped stress concentration area in the centre and the Southeast section had an energy release which was generally lower than $10^{4} \mathrm{~J}$ (Fig. 7). As the longwall panels had similar stress environments and mining conditions, the difference in released seismic energy levels is attributed to intrinsic factors, i.e., lithological properties such as coal strength and size scaling of fractures. The spatial clustering of large events and the spatial clustering of small events in Fig. 7 also support that the energy release is more associated with intrinsic factors (lithological properties) rather than extrinsic factors (mining activities). Therefore, it is believed that the difference in seismic energy released reflects the heterogeneity in the lithological properties of the underlying coal seam.

Figure 8 presents both seismic event counts and energyintensive regions associated with longwall coal mining around each LTCC panel. Analysis has been conducted only for regions of sizes larger than $20 \mathrm{~m}$, the average horizontal location accuracy of the microseismic monitoring system used in this research. Although the distribution of seismic intensive regions followed a different pattern in each panel, the energy-intensive events tended to occur where the stress environment was significantly disturbed, either within the mined-out areas or in the central part of the coal pillar. In contrast to the seismic intensive regions, the energy release intensive regions were distributed around the corresponding longwall panels but were not always overlapping with the regions where seismicity is most concentrated. However, it is noteworthy that both microseismicity intensive regions and seismic energy-intensive regions associated with coal mining in different panels are spatially connected. This strongly suggests that spatial and magnitude characteristics of the microseismicity induced by the LTCC mining at the panels are to a large extent dominated by the attributes of local fractures, which are characterised by spatial continuity throughout the coal seam.

\subsection{Energy Magnitude and Scaling}

Figure 9a presents the frequency-magnitude relationship for all the microseismicity recorded. The resulting bell-shaped histogram has been reported previously for mining-induced microseismicity at $-350 \mathrm{~m}$ depth at the same coal mine ( $\mathrm{Si}$ et al. 2015). The shape of the frequency-magnitude distribution for each panel resembles that for the whole dataset. Examples are given in Fig. 6b, c for the microseismicity around panels E.-80/B and E.-80/C respectively.

In view of the limited energy detection range of the geophones and relatively long distance between microseismic sources and geophones, a proportion of microseismicity with low energy levels could not have been picked up by the monitoring system. The minimum complete detection magnitude (or the magnitude of completeness), defined as the minimum magnitude at which all the microseismic events are detected in spatial and temporal scales, can be an indicator

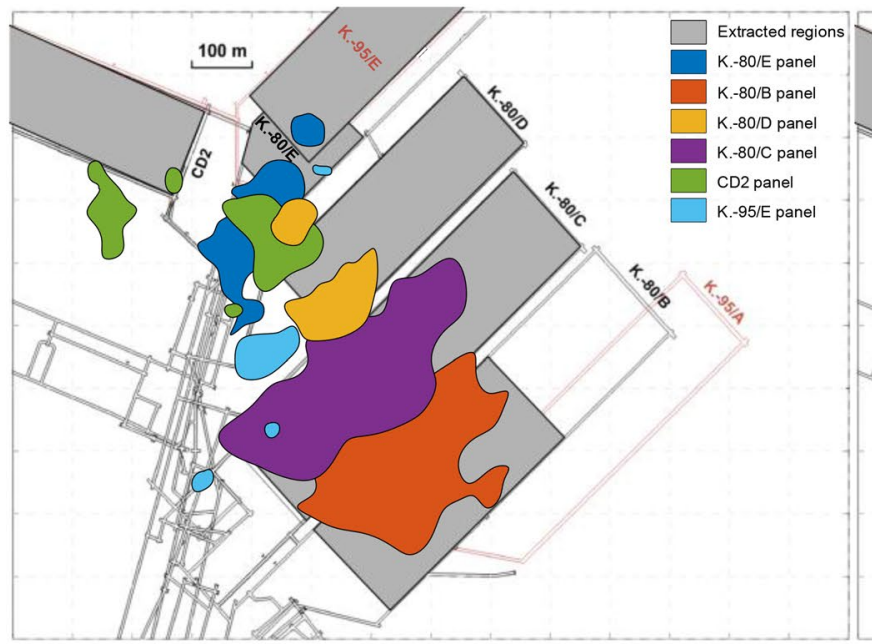

(a)

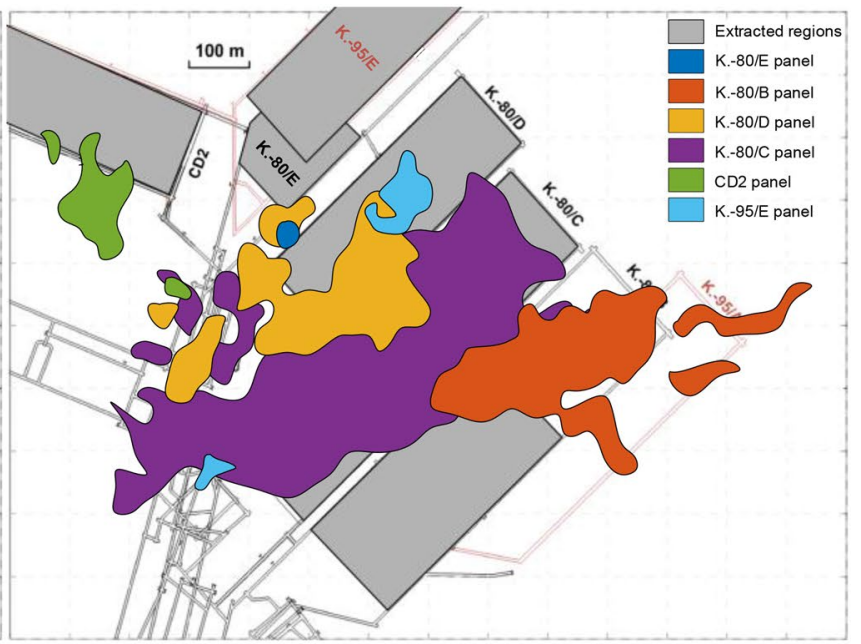

(b)

Fig. 8 Microseismicity intensive regions associated with different longwall panels: a event count intensive regions ( $>30 \%$ of the maximum seismicity density), and $\mathbf{b}$ seismic energy intensive regions ( $>103 \mathrm{~J} / \mathrm{m} 2)$ 


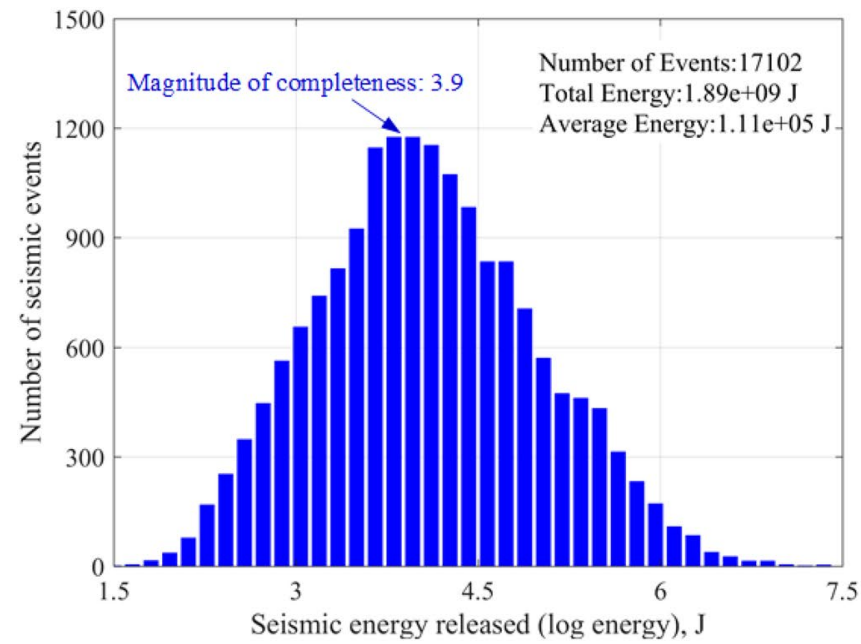

(a)

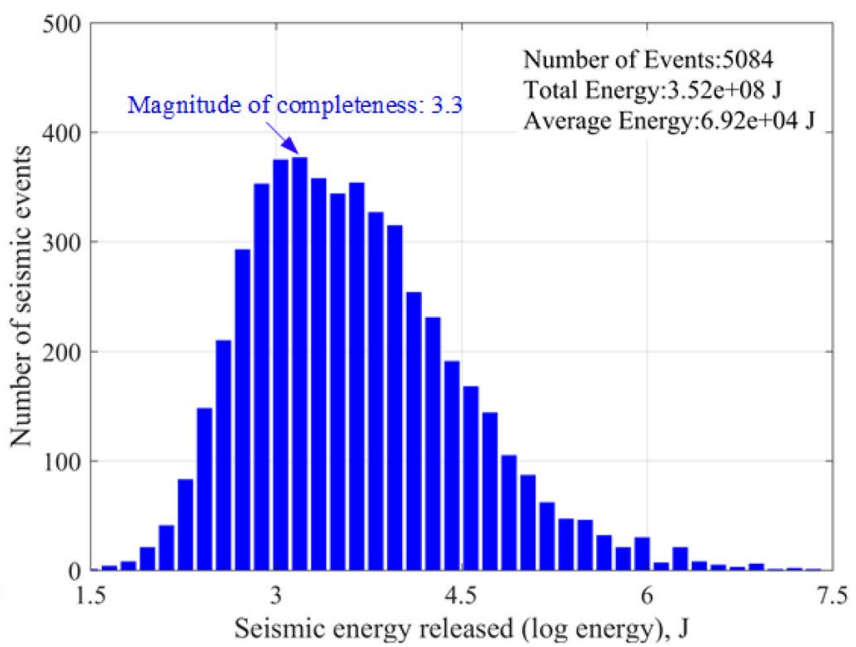

(b)

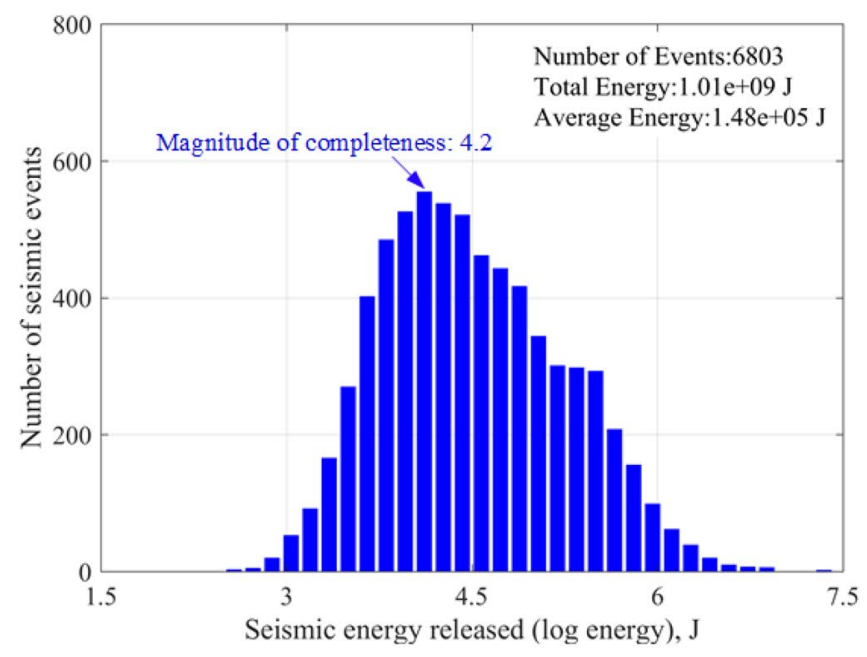

(c)

Fig. 9 Histograms of released energy of microseismic events recorded around: a all panels, b panel K.-80/B, and c panel K.-80/C

of the energy levels released around each panel (Woessner and Wiemer 2005; Ma et al. 2018b). The minimum complete detection magnitude for the whole dataset was estimated to be 3.9 by visualising the frequency-magnitude relationship of microseismicity, while those for microseismicity around each panel varied from 3.3 to 4.2 . The microseismicity around panel K.-80/C, whose seismic energy released constitutes more than half of the total energy released, has a relatively high minimum complete detection magnitude of 4.2 .

A well-known empirical observation in seismology is the Gutenberg-Richter law (Richter 1958), which expresses the proportional relationship between the event magnitude $M_{\mathrm{L}}$ and the cumulative number $N$ of seismic events with a magnitude greater than $M_{\mathrm{L}}$ : $\log _{10} N=a-b M_{\mathrm{L}}$

where $a$ and $b$ are constants, and $M_{\mathrm{L}}$ is a function of the seismic energy released:

$\log _{10} E=1.5 M_{\mathrm{L}}+4.8$

The parameter $b$, commonly referred to as the $b$ value, represents the relative abundance of small seismic events over large ones. The $b$ value is commonly around 1.0 in seismically active regions, meaning that the probability of magnitude 5.0 or larger seismic events would be 10 times that of magnitude 4.0 or larger events and 100 times that of magnitude 3.0 or larger events. The variation in the $b$ value has been widely employed in seismic risk assessment and 
pre-warning of hazardous seismic events (von Seggern 1980; Kijko and Funk 1994).

Figure 10 shows the cumulative frequency-magnitude relationship of the recorded microseismicity. The $b$ value in the Gutenberg-Richter law for microseismicity around each LTCC panel was obtained by a linear regression fitting starting from the minimum complete detection magnitude. The $b$ value fitted for seismic energy released for the whole dataset is 1, and those around the six LTCC panels fall into the range of $0.87-1.13$. Although the magnitude of completeness varies from panel to panel, the scaling of seismic energy released was relatively consistent between different panels.

\subsection{Evolutional Characteristics}

Figure 11 plots the daily event number, seismic energy released and the distance to the closest face-line, together with the daily face advance rate at two representative panels K.-80/B and K.-80/C (the remaining examples are presented in "Appendix"). The distance to the closest face-line position is taken as the distance of microseismicity to the nearest point of the closest active longwall face.

The results show that the daily microseismic intensity (top panel) closely follows the mine production schedule (bottom panel), with reduced values at weekends and holidays. In contrast, the average seismic energy and distance to the nearest face-line remained relatively consistent throughout, with the exception of a few outliers due to the scarcity of event numbers at weekends. The latter suggests that the face advance rate had much less impact on the magnitude and spatial distribution of microseismicity.

While the majority of microseismic events occurred within $400 \mathrm{~m}$ distance from the closest face-line, a small fraction was triggered as far as $800 \mathrm{~m}$ away from the active longwall face. Similar distance has also been reported by Marcak and Mutke (2013), where the hypocentres of strongest seismic events were 300-800 m deeper than the level of coal mining. The observation of microseismicity induced at a long distance from the active longwall face has been attributed to the reactivation of the fractures already under critical stress state by minute stress perturbations (Grasso and Sornette 1998). Elastic mechanics analysis indicates that stress environments at a distance of five times the excavation size may be perturbed. The extracted longwall panels had a width of 150-180 m, which gives rise to an influence zone of between 750 and $900 \mathrm{~m}$. For LTCC panels, an even larger area could be affected since coal around longwall faces fails and stress concentrations are shifted further ahead.

The results in Fig. 11 represent the spatial distribution of the majority of microseismicity with respect to faceline positions. However, the start and completion of operational longwall panels could result in a period of overlap in coal production at multiple longwall panels, and the resulting combined stress disturbance would in turn have an impact on the induced microseismicity accordingly. For example, the completion of panel K.-80/B in October 2016, panel K.-80/D (see "Appendix") in February 2017, and panel K.-80/C in February 2018 led to sharp rises in numbers of far-field microseismicity around panels K.80/D, K.-80/C and K.-95/E (see "Appendix"), respectively.

As the longwall face moved towards/away from the microseismic monitoring zone, a steady increase, as in the case of panel K.-95/E, or decline, as in the case of panel CD2, in the microseismic event counts was recorded, the latter being due to the increased attenuation in long travelling distances and reduced accuracy in locating event sources. Nevertheless, the average seismic energy and spatial distribution with respect to face-line positions were not

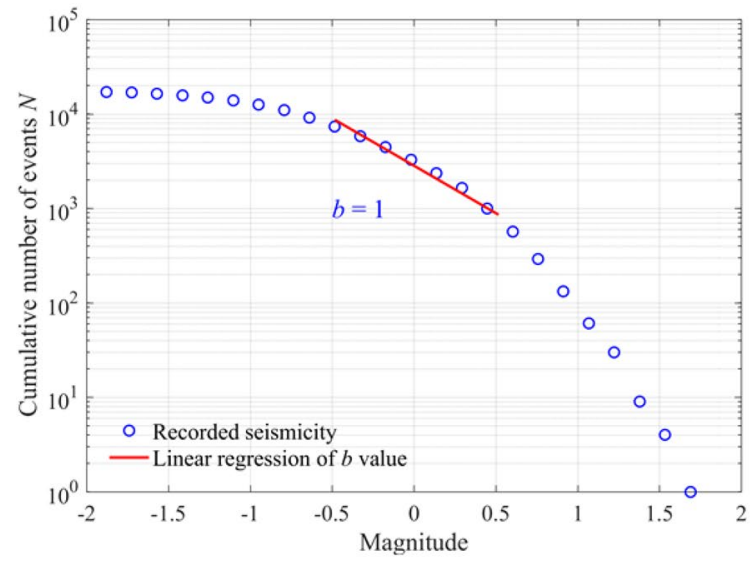

(a)

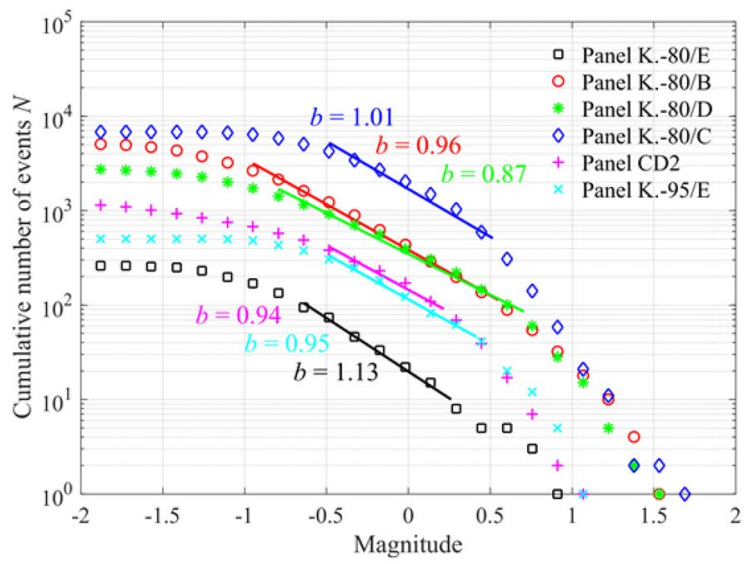

(b)

Fig. 10 Frequency-magnitude relationship of the recorded microseismicity around: a all panels, and $\mathbf{b}$ each panel 
Fig. 11 Evolutional characteristics of LTCC mining-induced microseismicity on a daily basis around: a panel K.-80/B, and $\mathbf{b}$ panel K.-80/C
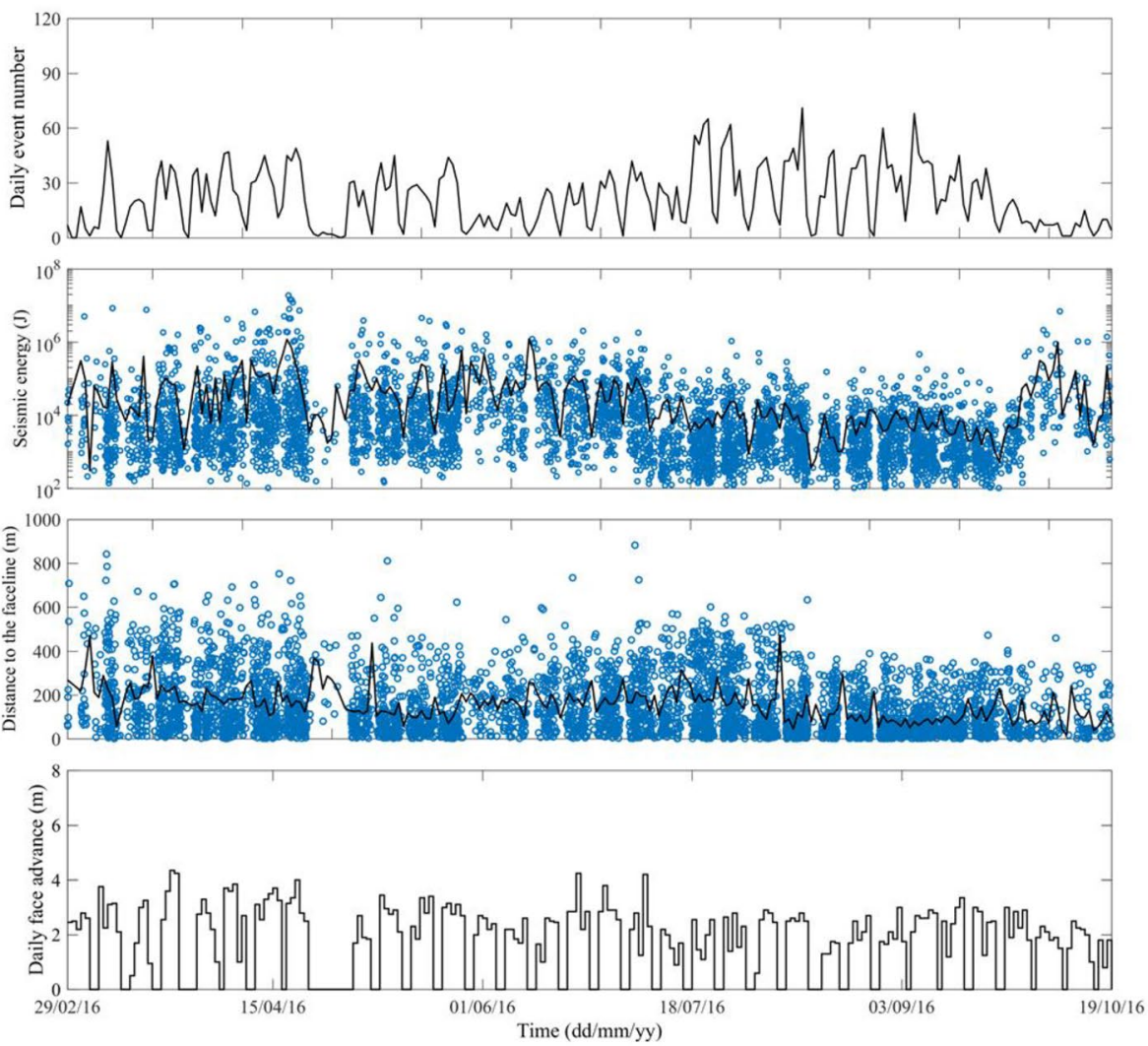

(a)
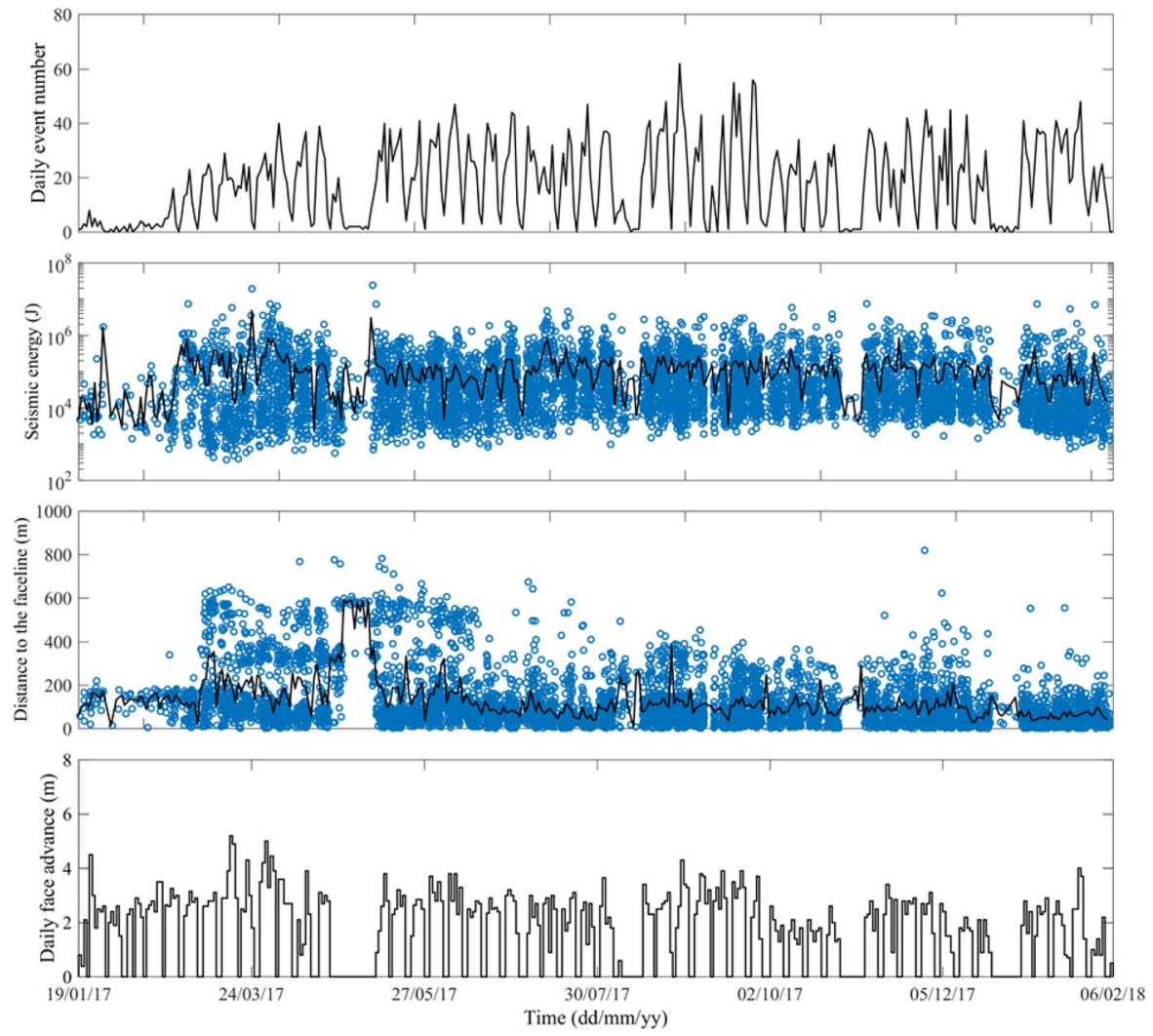

(b) 
influenced by the incomplete sampling of microseismic events.

In an effort to minimise deviations caused by the insufficient number of events, analyses of seismic energy, in terms of the estimation of $b$ value in the Gutenberg-Richter law and the box-and-whisker diagrams, were performed based on weekly events. To yield a reliable $b$ value, which represents the scaling of seismic energy, the regression fitting was made over a linear part of the weekly frequency-magnitude plots, while discarding those weeks with few microseismic events. The plot of box-and-whisker diagrams for each subgroup seismicity allows a better visual display of the seismic energy distribution through upper and lower quartiles and extremes. Box-and-whisker diagrams have the added advantage of taking up less space in exhibiting multi-group datasets in comparison to histograms without losing key information, such as the range of magnitudes, statistical dispersion, and skewness. Two representative examples of the results are presented in Fig. 12.

The $b$ values for the weekly microseismicity around each panel generally fluctuated around 1 (top panel, Fig. 9). As the $b$ value has an inverse correlation with the average seismic energy, the elevated level at panel K.-80/B during the period 17/07/16-02/10/16 indicates suppressed seismic energy release, and vice versa when it subsequently dropped to the normal level (Fig. 11a). Microseismicity around panel $\mathrm{K} .-80 / \mathrm{C}$ experienced a sharp decrease in the $b$ value as the average seismic energy increased from $13 / 02 / 17$, followed by a low- $b$ value period until 23/04/17 (Fig. 11b).

It is noted that the face advance rate had little impact on either the $b$ value or the average seismic energy. In those weeks when coal extraction was halted in particular, both the $b$ value and the average seismic energy remained fairly stable, albeit the number of newly generated microseismic events dropped significantly. This indicates that mine production as a trigger of microseismicity does not dominate the magnitude and scaling of the resulting energy release. Furthermore, this observation does not contradict the widely accepted view that higher face advance rates lead to more intense energy release and higher hazard potential (Tao et al. 2012; Cao et al. 2016; Li et al. 2016a). When the face advance rate is increased, the mined-out volume, the stress redistribution area and the number of activated fractures increase, leading to a higher probability of hazardous events. In addition, mining at high face advance rates does not allow sufficient time for surrounding rock/coal to achieve stress equilibrium, which also jeopardises the stability of coal seams.

In the box-and-whisker diagrams (middle panel, Fig. 12), the interquartile range, which is between the upper and lower quartiles, are more concentrated around the median value. Nearly symmetrical distribution of seismic energy with respect to the median value within the interquartile range during the majority of weeks is observed. However, the upper and lower extremes, represented by the 97th and 3th percentiles respectively in this work, are not symmetrical with respect to the median value. For most weeks, the top whisker (distance from the upper extreme to the median value) is longer than the bottom one, and the mean seismic energy is larger than the median value, both of which suggest that the distribution of released energy is positively skewed, corresponding to the elongated tails in the histograms of released microseismic energy (Fig. 9b, c).

\section{Discussion}

Field recorded microseismicity corresponding to the mining of eight longwall top coal caving panels over a 27-month coal production period were analysed with reference to concurrent face advance records and the stress disturbances from previous mining activities. The following conclusions were made:

(1) microseismicity occurred up to $800 \mathrm{~m}$ away from the extracted panel, which may be explained by the reactivation of fractures at critical stress states subjected to minute stress perturbations;

(2) the source-scaling property of microseismicity is dominated by that of natural fractures (Cao et al. 2018); and

(3) both spatial and energy distribution of mining-induced microseismicity is panel specific, which is believed to be governed by the attributes of underlying natural fractures.

These findings have provided further evidence for the fracture-slip seismicity-generation mechanism.

\subsection{Microseismic Characteristics Influenced by LTCC Mining}

The characteristics of longwall coal mining-induced microseismicity depend on the interplay of intrinsic and extrinsic factors. Intrinsic factors include primarily attributes of fractures, such as the spatial distribution (density and local heterogeneity), the length size and scaling, and mechanical properties (frictional coefficient). Extrinsic factors are the prevailing stress environments typically induced by production at longwall panels and stress perturbations from mining activities in the region. The fracture attributes in the field are largely unknown.

Analysis of the monitoring data in this work revealed how mine production influenced individual characteristic of induced microseismicity, which in turn can reveal to which extent each microseismic characteristic could reflect the fracture attributes. Figure 13 presents the daily event 

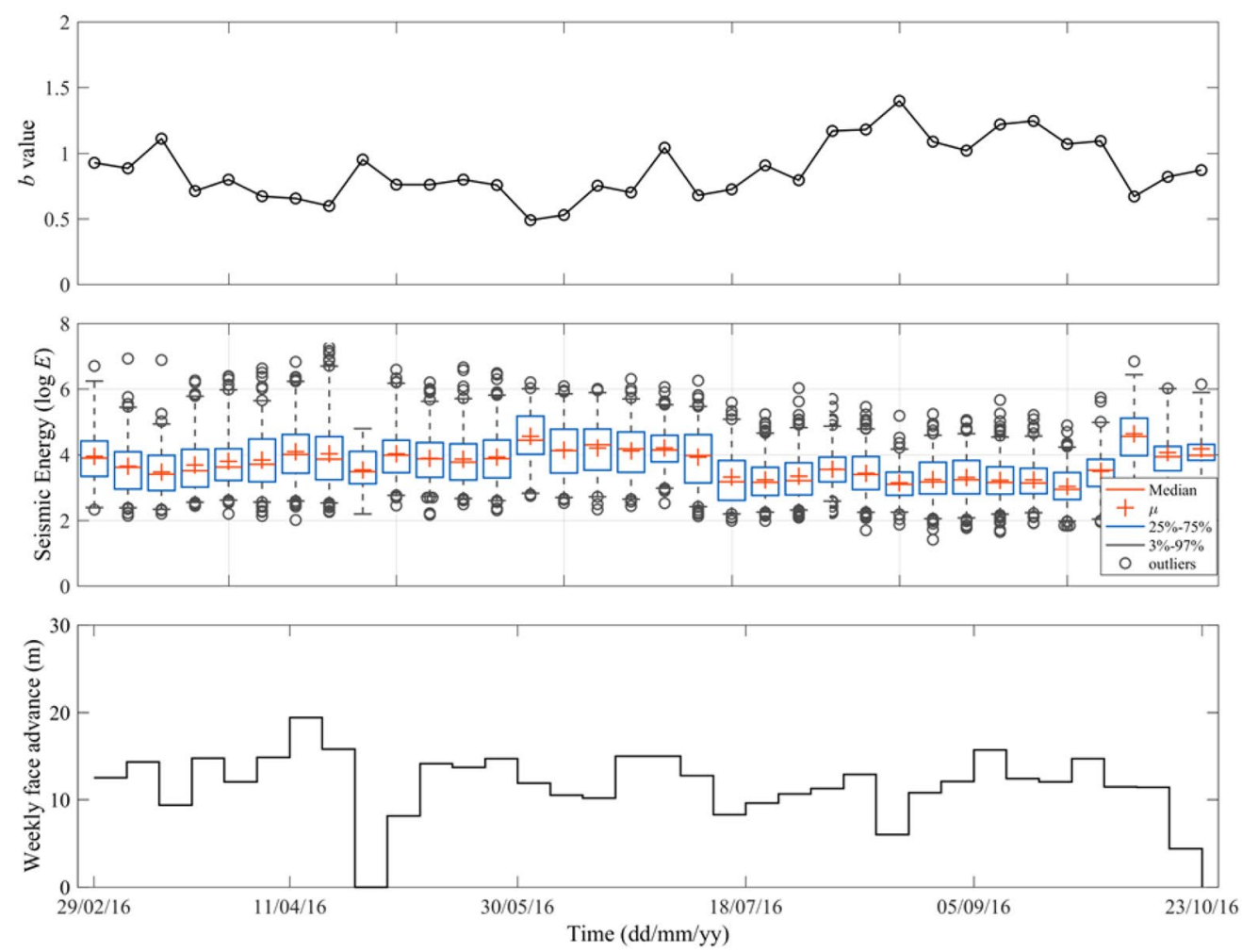

(a)
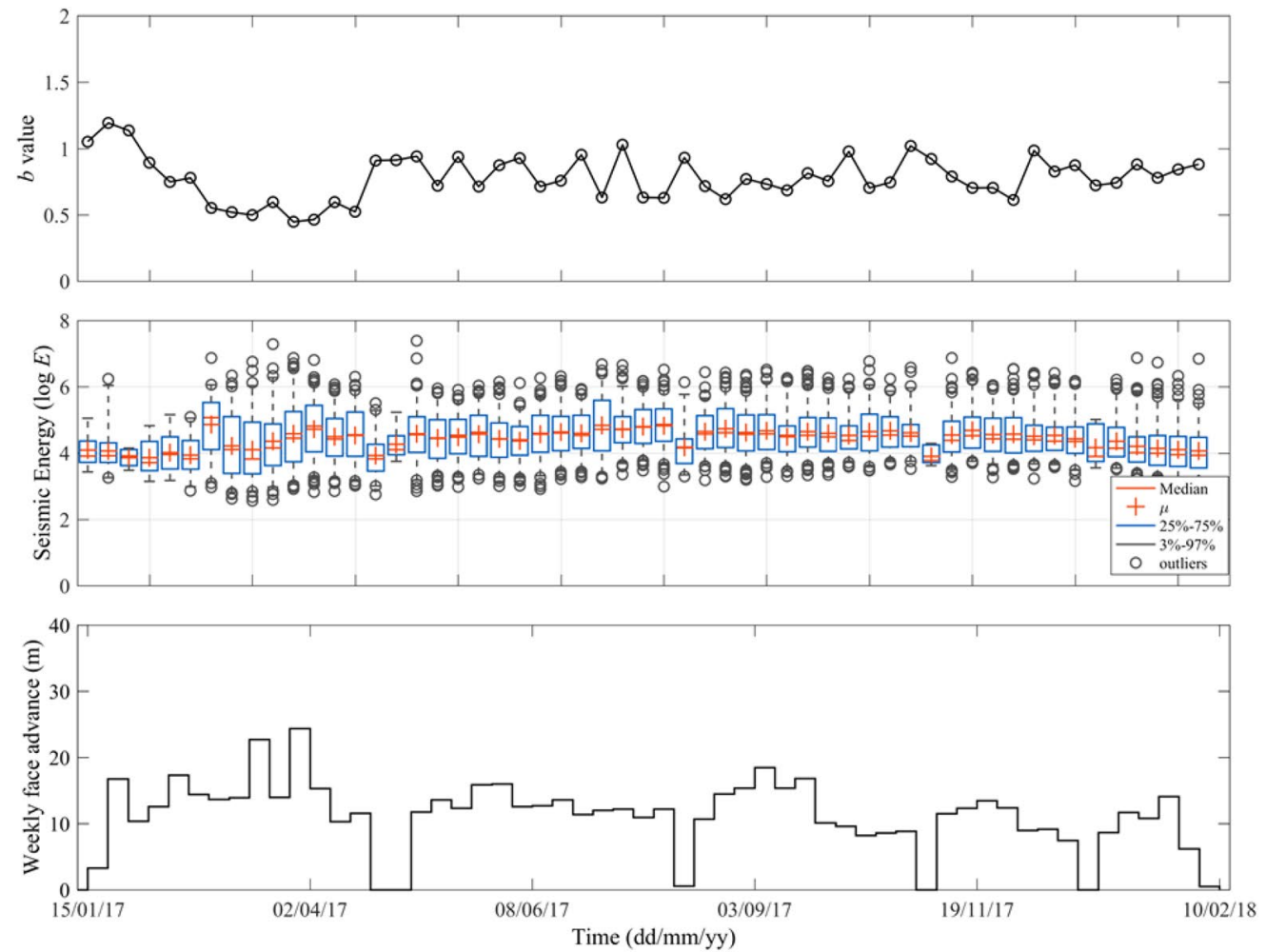

(b)

Fig. 12 Evolutional characteristics of LTCC mining-induced microseismicity on a weekly basis around: a panel K.-80/B, and b panel K.-80/C 


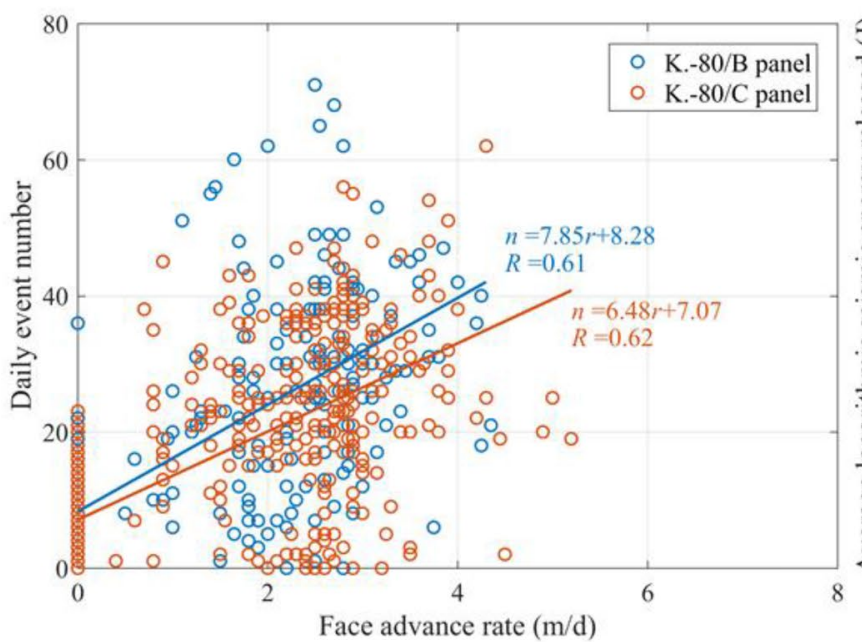

(a)

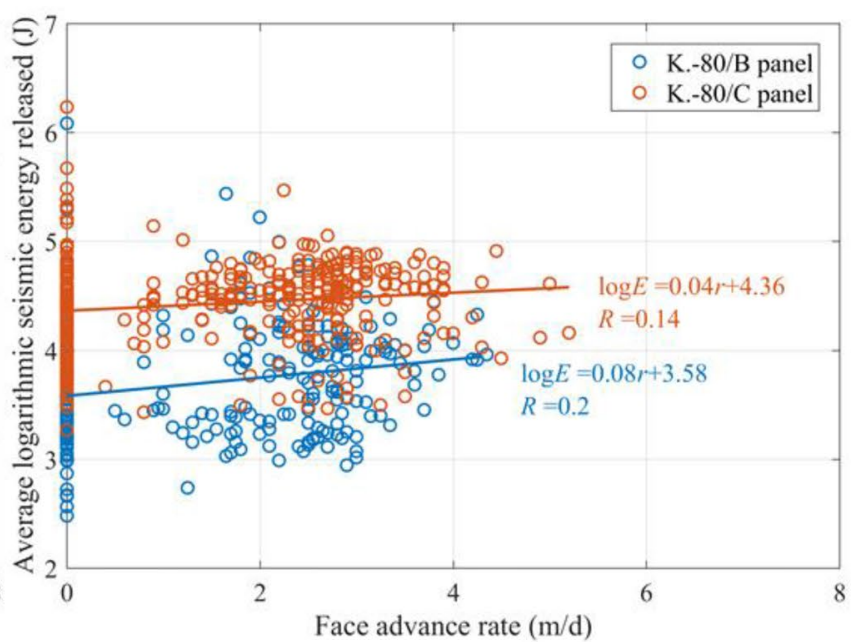

(b)

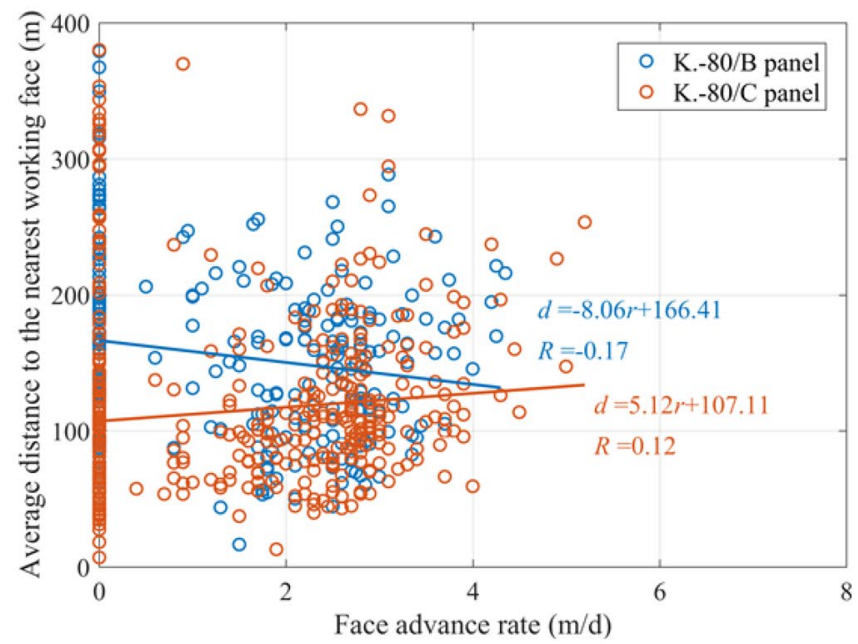

(c)

Fig. 13 The relationship between the daily event counts, average seismic energy released, average distance to the nearest operating longwall face and mining intensity

number, average seismic energy released, and average distance to the nearest working face against face advance rate for microseismicity around two LTCC panels. It can be seen from Fig. 13a that the daily event number is moderately correlated with the face advance rate, which is consistent with previous reports (Bishop et al. 1993; Shen et al. 2008; Si et al. 2015; Tang et al. 2018). This is because the number of slipped fractures triggered by mining activities is approximately proportional to the extracted volume of coal per unit time or the mining intensity. This also provides an explanation for observations that the amount of seismic energy released depends on the volume of extracted coal for South African mines (McGarr 1976), Czech and Polish mines (Głowacka 1992), and some German mines (Fritschen 2010). But the not so strong correlation between seismic intensity and mining progression is believed to be caused by the heterogeneous distribution of natural fractures throughout the coal seam.

Figure $13 \mathrm{~b}$ and $\mathrm{c}$ demonstrate that both the average seismic energy and the average distance to the nearest working face are poorly related to the face advance rate. This is consistent with the observations from China that the seismic energy release has no clear relationship with mining intensity in a coal mine ( $\mathrm{Li}$ et al. 2016b). It is believed that, although microseismicity is induced by the longwall coal production, its energy and spatial distribution are controlled by the attributes of natural fractures in the coal seam. Specifically, seismic energy released is dominated by the length size and scaling of fractures, while the spatial distribution of microseismicity is governed by that of local underlying fractures. This has significant implications in accurate evaluation of hazards and 
risk, and associated adjustment of face advance rate such that spatial and magnitude information of microseismicity is isolated from coal production and can be taken as independent variables.

\subsection{A Conceptual Model for Mining-Induced Microseismicity}

The focal mechanism of microseismicity provides implications for the failure type of rock mass. Moment tensor analysis is the conventional method to derive the focal mechanism based on the first-motion polarity and radiation patterns of microseismicity. In the analysis, a moment tensor can be decomposed into a double couple corresponding to shear failure, a compensated linear vector dipole representing uniaxial compression or tension, and an isotropic component denoting a volumetric change. Focal mechanism analysis of microseismicity recorded at Coal Mine Velenje was heavily constrained by the layout of seismic sensors installed and the resulting low number of activated sensors for each event recorded. Previous research on mining-induced microseismicity has reported that the shear component of the source mechanism is dominant leading to well-constrained doublecouple solutions, while there are relatively small non-shearing components (Young et al. 1989; Wiejacz 1991; Gibowicz 1993). Therefore, it is believed that mining-induced microseismicity at Coal Mine Velenje represents the shear failure mode of rock/coal, which is the activation of local underlying fractures in the far-field.

Assuming that rock has a single pre-existing fracture whose outward unit normal vector makes an angle $\beta$ with the direction of the maximum principal stress $\sigma_{1}$, Jaeger's "plane of weakness" model (Jaeger et al. 2009) suggests that failure of the rock is deemed to occur either at an angle given by the Mohr-Coulomb criterion, in which case $\sigma_{1}$ at failure will be governed by the strength of rock (cohesion $c$ and coefficient of friction $\mu$ ) and the minimum principal stresses $\sigma_{3}$, but independent of $\beta$ :

$\sigma_{1}=2 c\left[\left(1+\mu^{2}\right)^{1 / 2}+\mu\right]+\left[\left(1+\mu^{2}\right)^{1 / 2}+\mu\right]^{2} \sigma_{3}$

or along the fracture plane, where $\sigma_{1}$ at failure depends on the resistance along the fracture plane (cohesion along the fracture $c_{f}$ and $\mu$ ) and $\sigma_{3}$, and varies with $\beta$ :

$\sigma_{1}-\sigma_{3}=\frac{2\left(c_{f}+\mu \sigma_{3}\right)}{(1-\mu \cot \beta) \sin 2 \beta}$

The mode of failure will be determined by the smaller value of $\sigma_{1}$ given by Eqs. (4) and (5). Figure 14a presents the value of $\sigma_{1}$ needed to cause failure in a fracture-embedded rock as a function of $\beta$ under different confining stress conditions. Solutions for Eq. (5) exist only when $\phi<\beta<90^{\circ}(\phi$ is

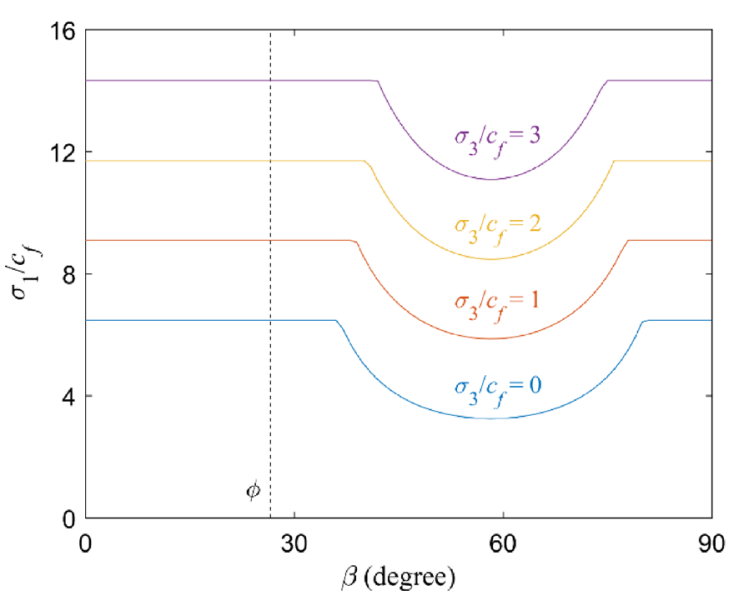

(a)

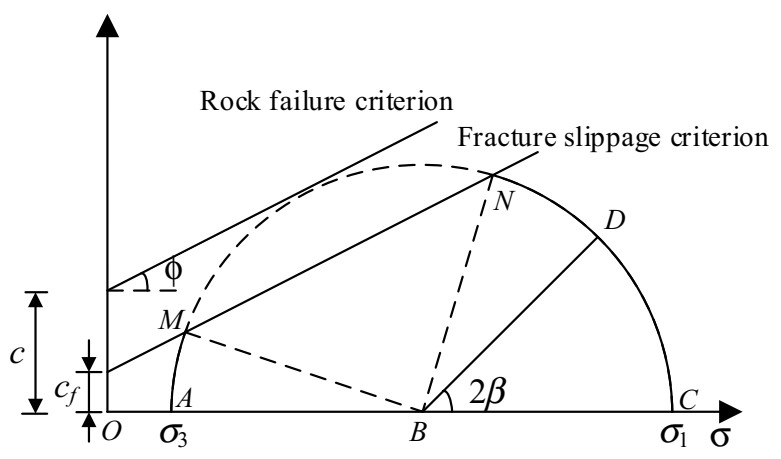

(b)

Fig. 14 a Variation of the value of $\sigma_{1}$ needed to cause failure in a fracture-embedded rock as a function of $\beta$ (for the case when $\mu=0.5$, $c=2 c_{f}$ ), and $\mathbf{b}$ a Mohr diagram illustrating two modes of failure for fracture-embedded rock (after Jaeger et al. 2009)

the frictional angle of the rock), and the range of $\beta$ for failure in the form of fracture slippage is symmetric with respect to $\phi / 2+45^{\circ}$, which is the angle given by the Mohr-Coulomb criterion.

The modes of failure for fracture-embedded rock are illustrated in a Mohr diagram in Fig. 14b. Given that the coefficient of friction is the same in the two failure modes, Mohr-Coulomb criteria for intact rock and for fracture slippage can be represented by two parallel lines, intersecting with the $\tau$ axis at $c$ and $c_{f}$, respectively. The normal and shear stresses along the fracture plane are represented by point $D$ in the $\sigma-\tau$ plane. Slippage along the fracture will not occur if the point $D$ falls between $\operatorname{arcs} A M$ or $N C$ of the Mohr circle but will occur if it lies within arc $M N$. Fractures whose stress states lie within arc $M N$ can be referred to as preferably oriented fractures. Therefore, it is believed that longwall coal mining-induced microseismicity is dominated by slippage of pre-existing preferably orientated fractures, rather than by failure of intact coal. 
Based on the analyses of stress concentration within the central coal pillar, recorded microseismicity, and continuous records of face advance discussed above, a conceptual model has been developed to describe the longwall top coal caving mining-induced microseismicity. Since progressive longwall mining can be considered as a plane strain problem, a cross-section of the multi-level LTCC mining layout at Coal Mine Velenje is depicted in Fig. 15. Pre-existing fractures within coal as potential sources of microseismicity are projected to the cross-section as $2 \mathrm{D}$ fracture traces. The distribution of fracture sizes in rock can be characterised by the lognormal, exponential, gamma or power-law (Bonnet et al. 2001). The power-law distribution has been increasingly applied in the characterisation of fracture scaling in recent years. The underlying physical cause is related to the formation of fracture systems in rock, which is the formation of a self-organised critical state. Conditions for the formation of rock fractures include stress conditions, rock properties, and intrinsic heterogeneity of rock. Fracture growth across scales in rock is a self-similar process arising from the initial heterogeneity of rock, and the power-law distribution is an intrinsic characteristic of this process. In addition, the absence of a characteristic length in the fracture growth process is another key argument in support of the power-law distribution. The power-law scaling of natural fractures in rock can be written as:

$n(l)=\alpha \cdot l^{-a}$

where $n(l)$ is the number of fractures with size $l$ per unit volume, $\alpha$ is the density term which gives the number of fractures with unit fracture size, and $a(>1)$ is the power-law scaling exponent which defines the relative abundance of fractures with different sizes within the population.

Longwall mining creates a highly fractured zone immediately ahead of the longwall face, and stress concentrates over a large region ahead of the fractured zone. The vertical stress abutment extends from the near face fracturing zone to the far-field. As the longwall face advances progressively, the abutment stress concentration moves forward, and creates incremental vertical stress $\Delta \sigma_{v}$, contributing to slippage of fractures at critical stress states. Fractures are considered to be activated in the form of microseismicity when the prevailing stresses satisfy the

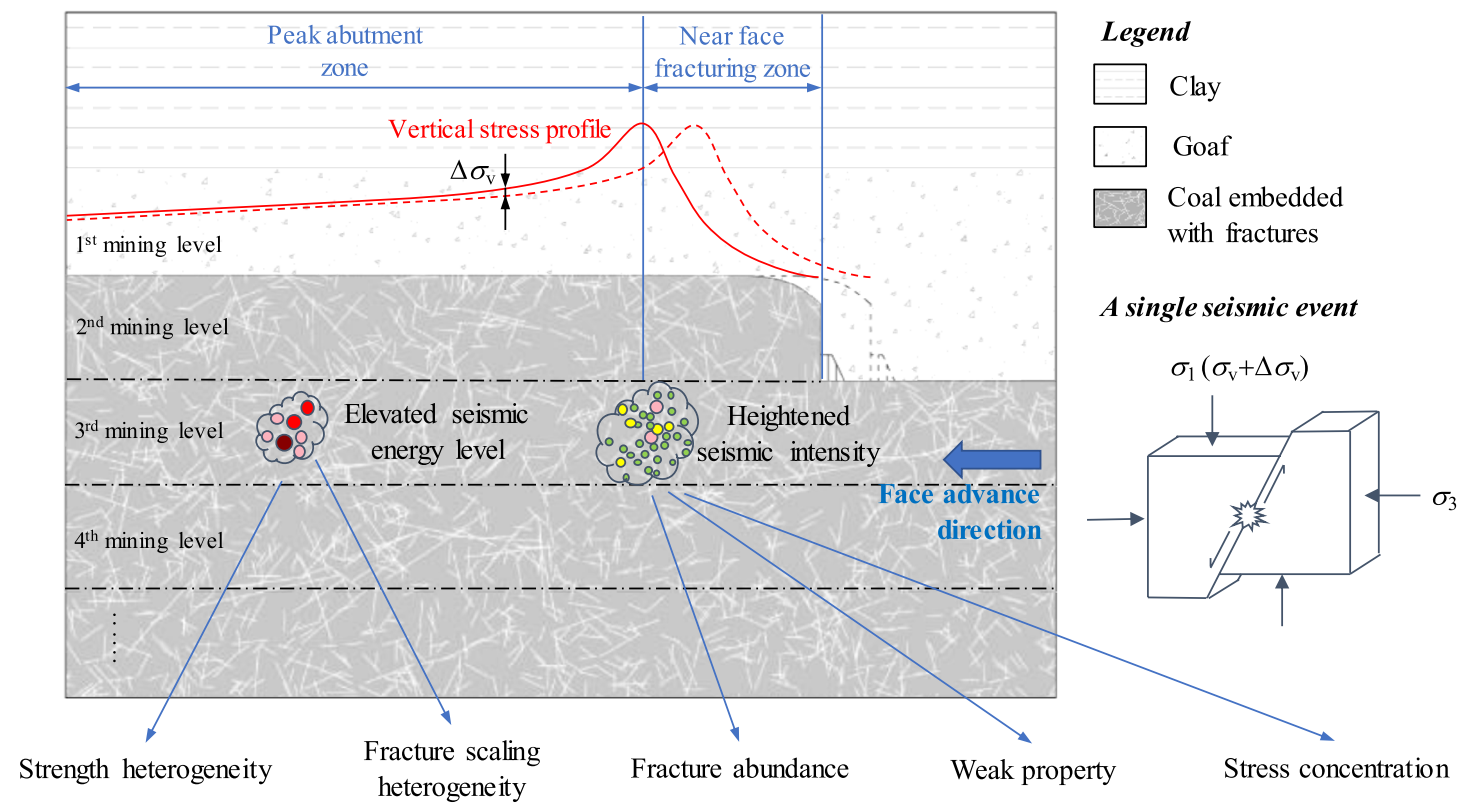

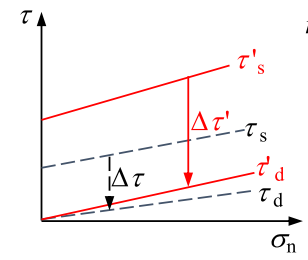

$\Delta \tau=\tau_{\mathrm{s}}-\tau_{\mathrm{d}}$

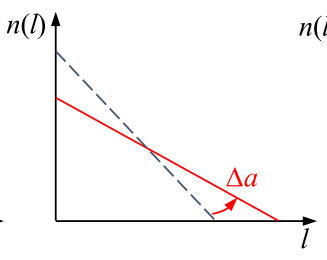

$n(l)=\alpha l^{-a}$

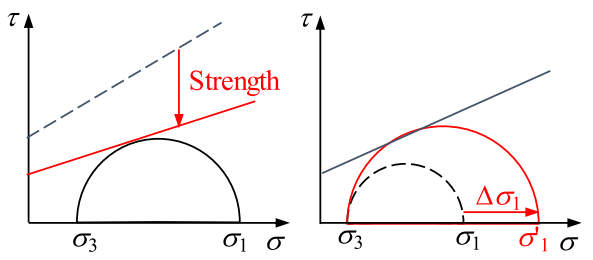

$\sigma_{1}-\sigma_{3}=\frac{2\left(c_{f}+\mu \sigma_{3}\right)}{(1-\mu \cot \beta) \sin 2 \beta}$

Fig. 15 Schematic illustration of longwall top coal caving induced microseismicity as a result of fracture slippage subjected to stress perturbations at Coal Mine Velenje 
Mohr-Coulomb slippage criterion (Eq. (5)). The change in shear stress $\Delta \tau$ along the fracture plane, i.e., the stress drop, can be approximated as the difference between the resistance $\tau_{\mathrm{sf}}$ prior to the slip and the dynamic strength $\tau_{\mathrm{df}}$ of the fracture surface:

$\Delta \tau=\tau_{\mathrm{sf}}-\tau_{\mathrm{df}}$

The static stress changes associated with progressive longwall mining can be quantified by changes of the Coulomb Failure Function, $\Delta$ CFF (Scholz 2002):

$\Delta \mathrm{CFF}=\Delta \tau-\mu \Delta \sigma_{n}$

where $\Delta \sigma_{\mathrm{n}}$ is the stress change normal to the fracture plane. Under favourable conditions, far-field fractures under critical stress states can be perturbed to slip subjected to minute stress perturbations. It was reported that incremental differential stress of $<1 \mathrm{MPa}$ is sufficient to trigger seismic instabilities, and that once triggered, stress variations of at least 1 order of magnitude less (around 0.1 MPa) could sustain seismic activities (Grasso and Sornette 1998). A statistical test conducted by Orlecka-Sikora (2010) indicated that a $\Delta \mathrm{CFF}$ as little as $0.005 \mathrm{MPa}$ has a significantly favourable effect on the occurrence of mining-induced seismicity experienced at a copper mining district in Poland.

Longwall coal mining-induced microseismicity can be considered as a sampling of fractures within the coal seam, conditional on the prevailing stress environment, coal properties and fracture attributes. The triggered microseismicity and associated energy release can be analysed in terms of the three aforementioned mechanisms: fracture abundance, slip criterion, and resulting stress drop. Figure 15 demonstrates possible causes for two types of microseismicity: elevated seismic energy level and heightened microseismic intensity. The elevated seismic energy level can be significantly attributed to:

(1) large stress drop along the fracture surface during slip. The stress drop during the fracture slippage is dominated by the shear strength (the cohesion and frictional angle) of the fracture surface, according to Eq. (7). Strong shear strength of the fracture surface will lead to a large stress drop once the fracture is activated, as shown in the first diagram in Fig. 15.

(2) source-scaling heterogeneity of fractures. The seismic energy released is proportional to the cube of fracture size (Cao et al. 2018). The relative abundance of large fractures, represented by a decrease in the power-law exponent in Eq. (6) (the second diagram in Fig. 15), increases the seismic energy release by increasing the proportion of large microseismicity.
Three possible reasons responsible for heightened microseismic intensity are:

(1) the presence of highly fracture-populated regions. The abundance of pre-existing fractures in the proximity of mine workings, represented by an increase in the density term in Eq. (6) (the third diagram in Fig. 15), indicates that more fractures are deemed to be activated at similar mining conditions and stress environments. This is supported by field observation that most microseismicity and almost all rockbursts occur close to existing or newly-formed fracture zones (Ma et al. 2018a).

(2) weak fracture properties. The shear strength of the fracture surface is a function of its cohesion and frictional angle. As shown in the fourth diagram in Fig. 15, weak fracture properties (either low cohesion or frictional angle) lower the Mohr-Coulomb failure envelope, contributing to the slippage of more fractures.

(3) high-stress concentration. As presented in the fifth diagram in Fig. 15, stress concentration destabilises fractures in rock/coal by bringing the Mohr stress circle towards the failure envelope, resulting in an increased number of microseismicity.

\section{Conclusions}

Microseismic monitoring was carried out around a central unexploited coal pillar and eight surrounding LTCC panels at Coal Mine Velenje over a 27-month coal production period. The temporal, spatial and magnitude distribution of microseismicity and their evolutional characteristics around six completed longwall panels were analysed. The following observations were made:

- Microseismicity is mostly concentrated around the extracted longwall panels and the kidney-shaped stress concentration region within the central coal pillar, although some events can occur as far as $800 \mathrm{~m}$ away from the closest longwall face.

- The microseismic intensity and energy range vary from panel to panel even in the same mining region, but both seismic count and energy intensive areas associated with coal mining in different panels are spatially connected.

- Microseismic event counts frequency is moderately correlated with mining intensity, while seismic energy magnitude and spatial distribution are poorly related with mining intensity.

Research has demonstrated that spatial and magnitude characteristics of microseismicity are dominated by attributes of underlying natural fractures, except that the event 
counts frequency is further influenced by the volume of extracted coal (or the mining intensity). Since attributes of fractures embedded in geomaterials are spatially continuous, fractures that are triggered close in time and space tend to have similar characteristics.

A conceptual model has been developed to explain the observations made by interpreting mining-induced microseismicity as slippages of natural fractures in response to progressive longwall mining at Coal Mine Velenje. The conceptual model developed highlights the role of pre-existing natural fractures in controlling microseismic characteristics throughout the coal seam. Insights from the conceptual model can also provide directional guidance in probabilistic forecasting and numerical modelling of mining-induced microseismicity. The model provides a sound physical foundation for evaluating the characteristics of microseismicity to be triggered during progressive coal mining if the attributes of local fractures are estimated from previous microseismic records. However, the impacts of fracture abundance and mining intensity on the event counts frequency need to be decoupled, and the recorded microseismicity should be interpreted in such a way that the processed data only contains information regarding attributes of local fractures. This is yet another challenge the authors are aiming to address in their ongoing research.

Acknowledgements This research waas carried out as part of the European Commission Research Fund for Coal and Steel (RFCS) funded project "Monitoring, Assessment, Prevention and Mitigation of Rock Burst and Gas Outburst Hazards in Coal Mines-MapROC", Grant No: RFCR-CT-2015-00005. The first author acknowledges the UK Engineering and Physical Sciences Research Council (EPSRC) scholarship awarded by the Faculty of Engineering at Imperial College London. Wu Cai would like to thank the China Postgraduate Council International Postdoctoral Exchange Fellowship Program (Grant No. 20170060).

\section{Compliance with Ethical Standards}

Conflict of interest The authors declare that they have no conflict of interest.

Open Access This article is licensed under a Creative Commons Attribution 4.0 International License, which permits use, sharing, adaptation, distribution and reproduction in any medium or format, as long as you give appropriate credit to the original author(s) and the source, provide a link to the Creative Commons licence, and indicate if changes were made. The images or other third party material in this article are included in the article's Creative Commons licence, unless indicated otherwise in a credit line to the material. If material is not included in the article's Creative Commons licence and your intended use is not 
Fig. 16 Evolutional characteristics of microseismicity on a daily basis
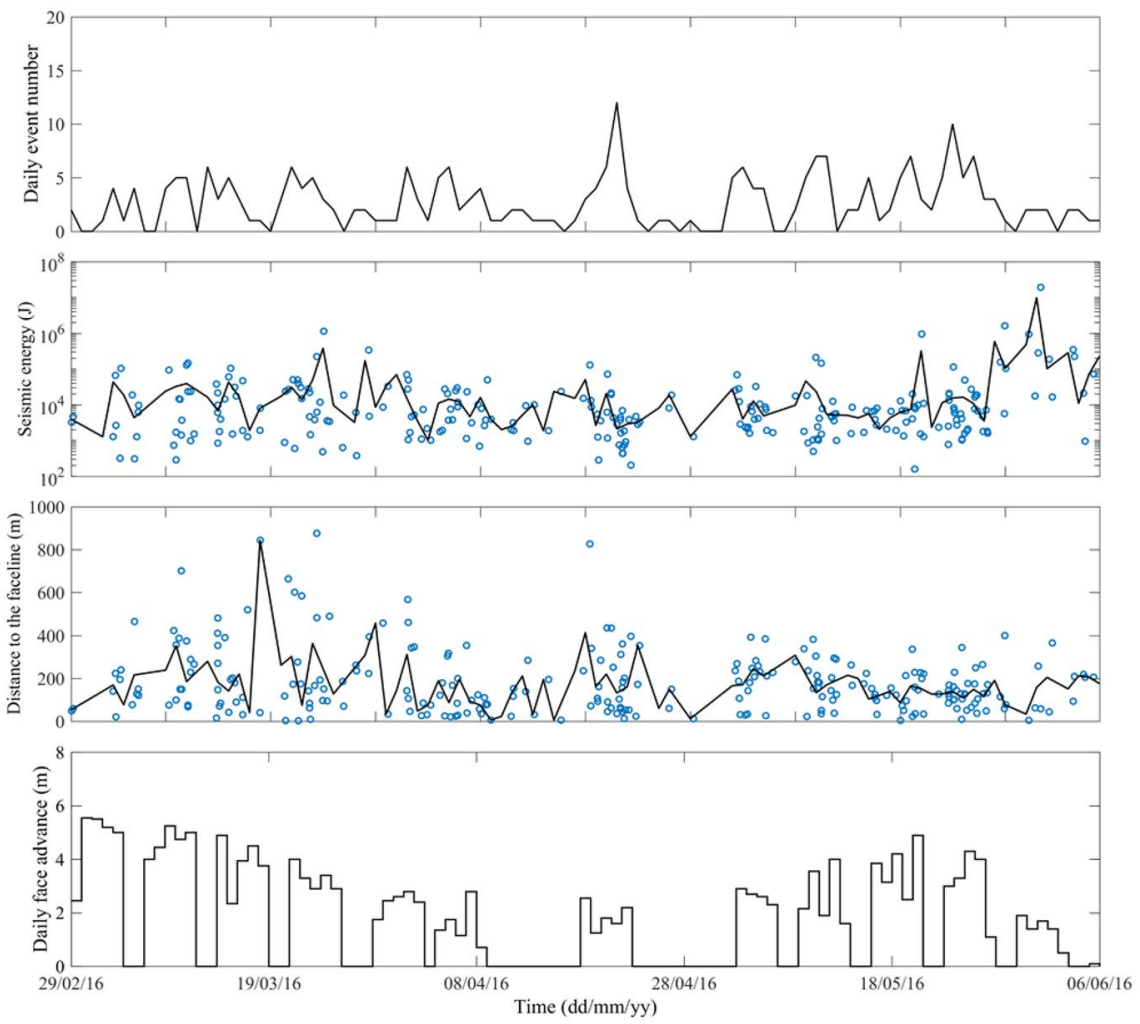

(a) panel E.-80/E
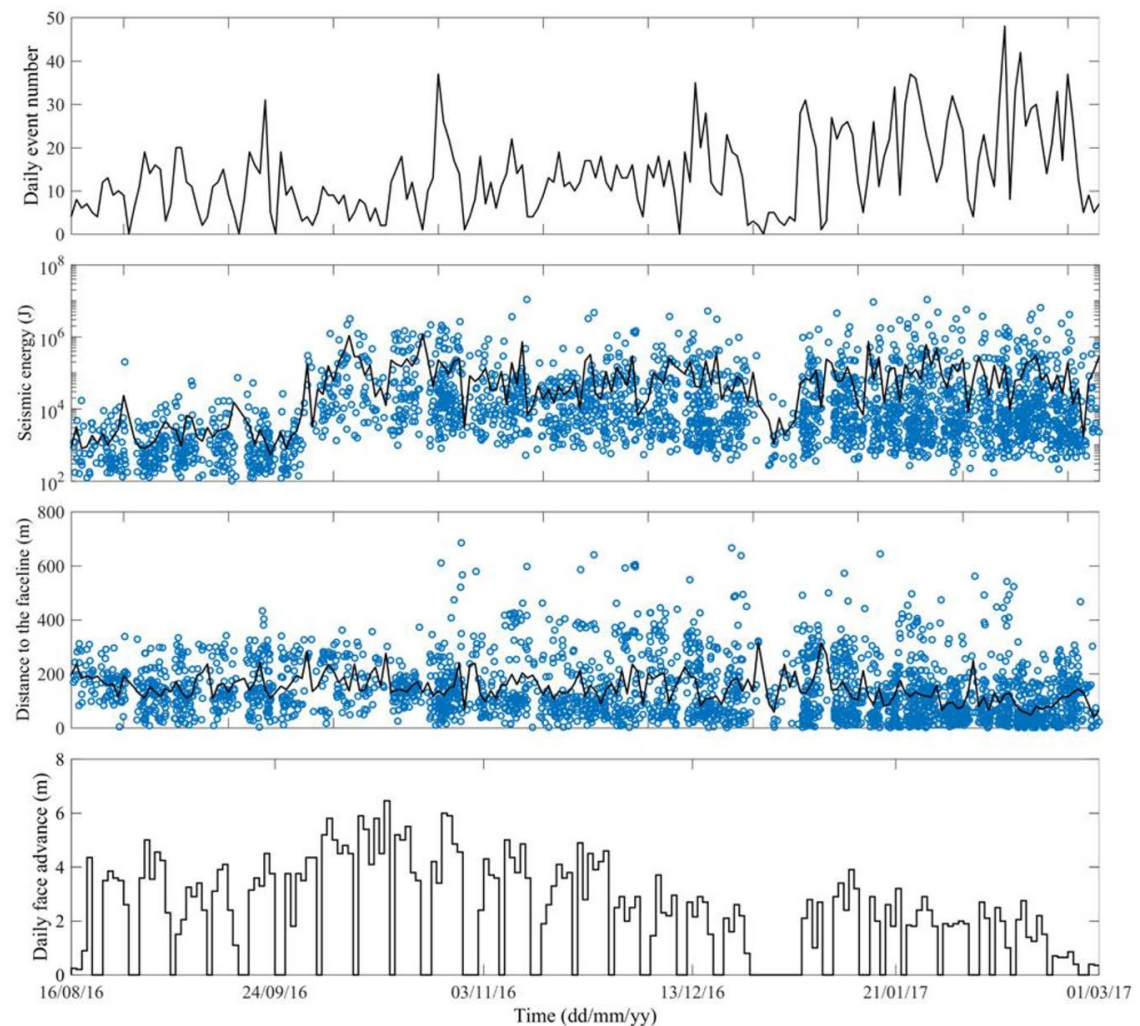

(b) panel E.-80/D 
Fig. 16 (continued)
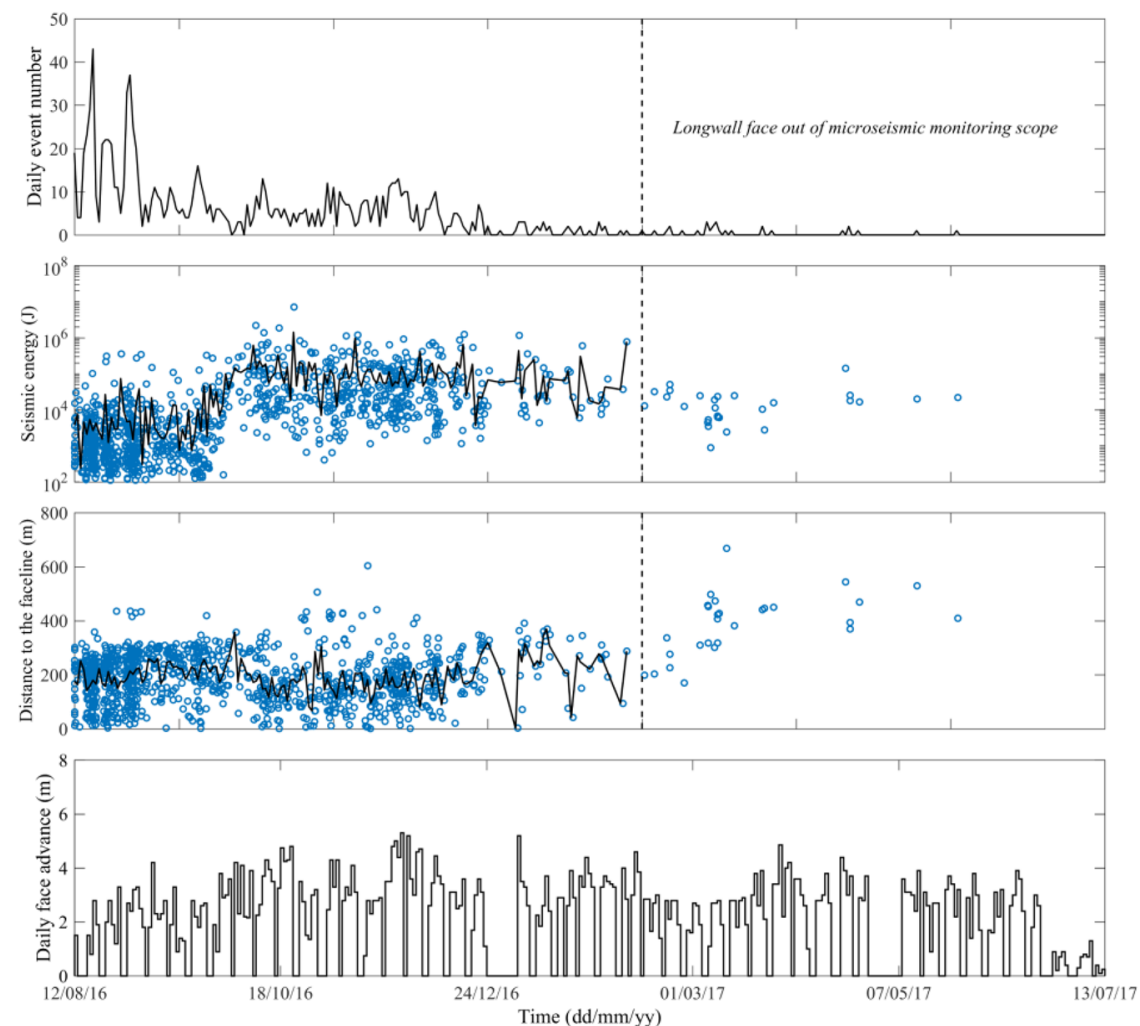

(c) panel CD2
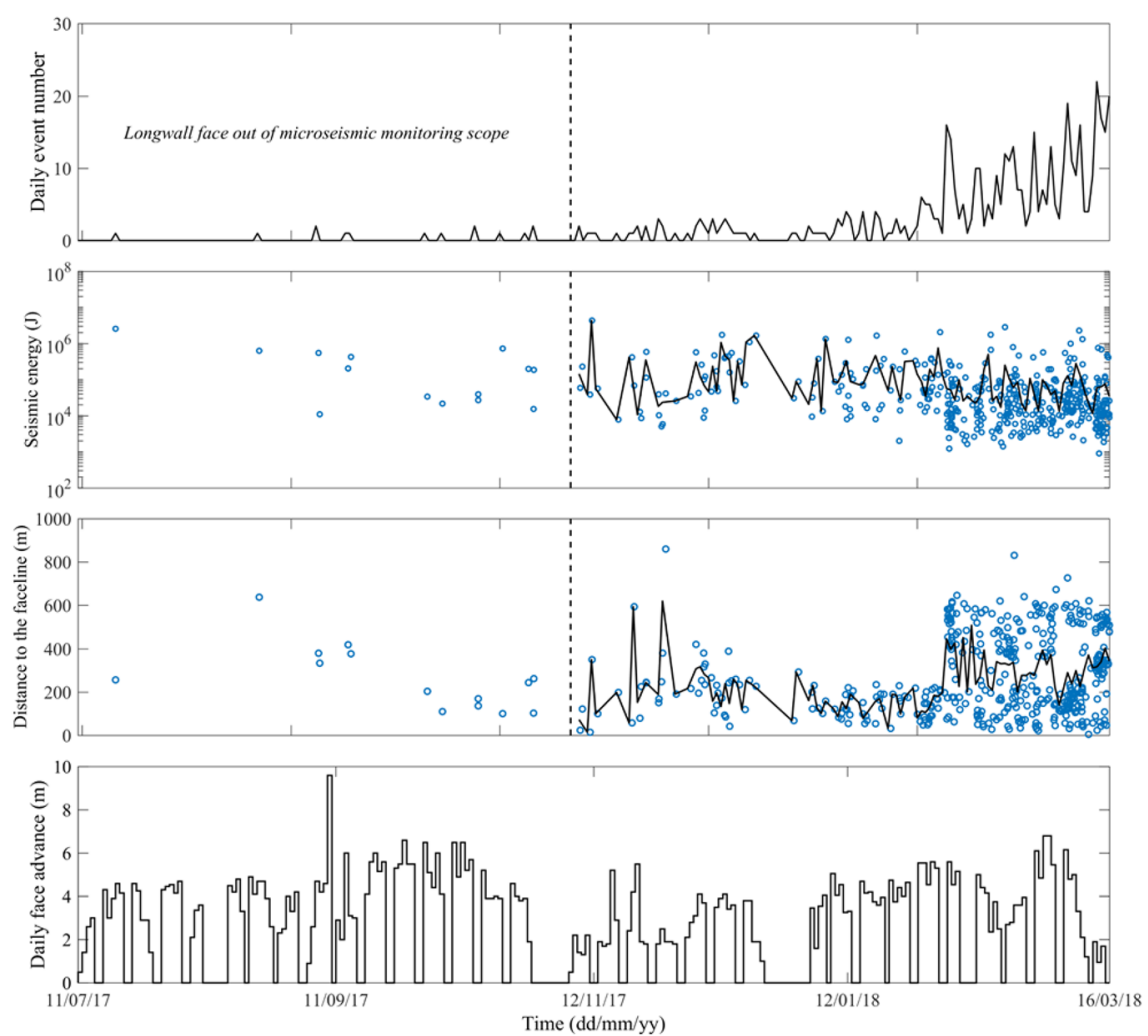

(d) panel K.-95/E 
permitted by statutory regulation or exceeds the permitted use, you will need to obtain permission directly from the copyright holder. To view a copy of this licence, visit http://creativecommons.org/licenses/by/4.0/.

\section{Appendix}

See Fig. 16.

\section{References}

Bishop I, Styles P, Allen M (1993) Mining-induced seismicity in the Nottinghamshire Coalfield. Q J Eng Geol Hydrogeol 26:253-279. https://doi.org/10.1144/GSL.QJEGH.1993.026.004.03

Bonnet E, Bour O, Odling NE et al (2001) Scaling of fracture systems in geological media. Rev Geophys 39:347-383. https://doi. org/10.1029/1999RG000074

Brezigar A (1986) Premogova plast Rudnika lignita Velenje (Coal seam of the Velenje coal mine). Geol Razpr poročila 28:319-336

Cao W, Li X, Tao M, Zhou Z (2016) Vibrations induced by high initial stress release during underground excavations. Tunn Undergr Sp Technol 53:78-95. https://doi.org/10.1016/j.tust.2016.01.017

Cao W, Shi J, Si G et al (2018) Numerical modelling of microseismicity associated with longwall coal mining. Int J Coal Geol 193:3045. https://doi.org/10.1016/j.coal.2018.04.010

Cao W, Shi J, Durucan S et al (2019) Numerical modelling of anomalous microseismicity influenced by lithological heterogeneity in longwall top coal caving mining. Int J Coal Geol 216:103305

Fritschen R (2010) Mining-induced seismicity in the Saarland, Germany. Pure Appl Geophys 167:77-89. https://doi.org/10.1007/ s00024-009-0002-7

Gibowicz SJ (1993) Keynote address: seismic moment tensor and the mechanism of seismic events in mines. Proc Rockbursts Seism Mines Kingston 1993:149-155

Głowacka E (1992) Application of the extracted volume of a deposit as a measure of deformation for seismic hazard evaluation in mines. Tectonophysics 202:285-290. https://doi.org/10.1016/00401951(92)90114-L

Grasso J-R, Sornette D (1998) Testing self-organized criticality by induced seismicity. J Geophys Res Solid Earth 103:29965-29987. https://doi.org/10.1029/97JB01344

Hassani H, Hloušek F, Alexandrakis C, Buske S (2018) Migrationbased microseismic event location in the Schlema-Alberoda mining area. Int J Rock Mech Min Sci 110:161-167. https://doi. org/10.1016/j.jirmms.2018.08.002

Jackson LJ (1984) Outbursts in coal mines. IEA Coal Research, London

Jaeger JC, Cook NGW, Zimmerman R (2009) Fundamentals of rock mechanics. Wiley, Chichester

Jeromel G, Medved M, Likar J (2010) An analysis of the geomechanical processes in coal mining using the velenje mining method. Acta Geotech Slov 7(1):31-45

Kijko A, Funk CW (1994) The assessment of seismic hazards in mines. J South Afr Inst Min Metall 94:179-185

Kozłowska M, Orlecka-Sikora B, Rudziński Ł et al (2016) Atypical evolution of seismicity patterns resulting from the coupled natural, human-induced and coseismic stresses in a longwall coal mining environment. Int J Rock Mech Min Sci 86:5-15. https://doi. org/10.1016/j.ijrmms.2016.03.024
Lasocki S (1993) Statistical short-term prediction in mining induced seismicity. In: Young RP (ed) Rockbursts and seismicity in mines. Balkema, Rotterdam, pp 211-216

Lei Q, Latham J, Tsang C (2017) The use of discrete fracture networks for modelling coupled geomechanical and hydrological behaviour of fractured rocks. Comput Geotech 85:151-176. https://doi. org/10.1016/j.compgeo.2016.12.024

Li X, Cao W, Tao M et al (2016a) Influence of unloading disturbance on adjacent tunnels. Int J Rock Mech Min Sci 84:10-24. https:// doi.org/10.1016/j.ijrmms.2016.01.014

Li Y, Yang TH, Liu HL et al (2016b) Real-time microseismic monitoring and its characteristic analysis in working face with highintensity mining. J Appl Geophys 132:152-163. https://doi. org/10.1016/j.jappgeo.2016.07.010

Likar J, Medved M, Lenart M et al (2012) Analysis of geomechanical changes in hanging wall caused by longwall multi top caving in coal mining. J Min Sci 48:135-145

Ma T, Tang C, Tang S et al (2018a) Rockburst mechanism and prediction based on microseismic monitoring. Int J Rock Mech Min Sci 110:177-188. https://doi.org/10.1016/j.ijrmms.2018.07.016

Ma X, Westman E, Slaker B et al (2018b) The b-value evolution of mining-induced seismicity and mainshock occurrences at hardrock mines. Int J Rock Mech Min Sci 104:64-70. https://doi. org/10.1016/j.ijrmms.2018.02.003

Marcak H, Mutke G (2013) Seismic activation of tectonic stresses by mining. J Seismol 17:1139-1148. https://doi.org/10.1007/s1095 0-013-9382-3

Markič M, Sachsenhofer RF (2010) The Velenje lignite: its petrology and genesis. Geological Survey of Slovenia, Ljubljana

McGarr A (1976) Seismic moments and volume changes. J Geophys Res 81:1487-1494

McKavanagh BM, Enever JR (1980) Developing a microseismic outburst warning system. In: In Proceedings of the second conference on acoustic emission/microseismic activity in geologic structures and materials. pp 211-225

Mutke G (2008) Stability of the underground mine workings in the near field zone of seismic events. 21st world mining congress: underground mine environment. The Fundation for the AGH, Kraków, pp 89-97

Orlecka-Sikora B (2010) The role of static stress transfer in mining induced seismic events occurrence, a case study of the Rudna mine in the Legnica-Glogow Copper District in Poland. Geophys J Int 182:1087-1095. https://doi.org/10.1111/j.1365246X.2010.04672.x

Richter CF (1958) Elementary Seismology. WH. Freeman and Company, San Francisco

Rutqvist J, Rinaldi AP, Cappa F et al (2016) Fault activation and induced seismicity in geological carbon storage-Lessons learned from recent modeling studies. J Rock Mech Geotech Eng 8:789_ 804. https://doi.org/10.1016/j.jrmge.2016.09.001

Sato K, Fujii Y (1988) Induced seismicity associated with longwall coal mining. Int J Rock Mech Min Sci 25:253-262. https://doi. org/10.1016/0148-9062(88)90002-2

Scholz CH (2002) The mechanics of earthquakes and faulting. Cambridge University Press, Cambridge

Shah AK, Keller GR (2017) Geologic influence on induced seismicity: constraints from potential field data in Oklahoma. Geophys Res Lett 44:152-161. https://doi.org/10.1002/2016GL071808

Shearer PM (1975) Introduction to Seismology. Cambridge University Press, Cambridge

Shen B, King A, Guo H (2008) Displacement, stress and seismicity in roadway roofs during mining-induced failure. Int J Rock Mech Min Sci 45:672-688. https://doi.org/10.1016/j.ijrmm s.2007.08.011 
Si G, Durucan S, Jamnikar S et al (2015) Seismic monitoring and analysis of excessive gas emissions in heterogeneous coal seams. Int $\mathbf{J}$ Coal Geol 149:41-54. https://doi.org/10.1016/j.coal.2015.06.016

Staszek M, Orlecka-Sikora B, Leptokaropoulos K et al (2017) Temporal static stress drop variations due to injection activity at The Geysers geothermal field, California. Geophys Res Lett 44:71687176. https://doi.org/10.1002/2017GL073929

Styles P, Emsley SJ, Jowitt T (1988) Microseismic monitoring for the prediction of outbursts at Cynheidre Colliery, Dyfed, S. Wales. Geol Soc London Eng Geol Spec Publ 5:423-433. https://doi. org/10.1144/GSL.ENG.1988.005.01.47

Tang Z, Liu X, Xu Q et al (2018) Stability evaluation of deep-buried TBM construction tunnel based on microseismic monitoring technology. Tunn Undergr Sp Technol 81:512-524. https://doi. org/10.1016/j.tust.2018.08.028

Tao M, Li X, Wu C (2012) Characteristics of the unloading process of rocks under high initial stress. Comput Geotech 45:83-92. https ://doi.org/10.1016/j.compgeo.2012.05.002

von Seggern D (1980) A random stress model for seismicity statistics and earthquake prediction. Geophys Res Lett 7:637-640

Wiejacz P (1991) Investigation of focal mechanisms of mine tremors by the moment tensor inversion. Pol) Ph D Thesis, Inst Geophys Pol Acad Scl, Warsaw

Woessner J, Wiemer S (2005) Assessing the quality of earthquake catalogues: estimating the magnitude of completeness and its uncertainty. Bull Seismol Soc Am 95:684-698. https://doi. org/10.1785/0120040007
Woodward K, Wesseloo J, Potvin Y (2018) A spatially focused clustering methodology for mining seismicity. Eng Geol 232:104-113

Young RP, Talebi S, Hutchins DA, Urbancic TI (1989) Analysis of mining-induced microseismic events at Strathcona mine, Sudbury, Canada. In: Gibowicz S.J. (eds) Seismicity in Mines. Springer, pp 455-474

Young RP, Collins DS, Hazzard J, et al (2005) Seismic validation of 3-D thermo-mechanical models for the prediction of rock damage around radioactive waste packages in geological repositories

Yu B, Zhao J, Xiao H (2017) Case study on overburden fracturing during longwall top coal caving using microseismic monitoring. Rock Mech Rock Eng 50:507-511. https://doi.org/10.1007/s0060 3-016-1096-8

Zhai G, Shirzaei M (2018) Fluid injection and time-dependent seismic hazard in the Barnett Shale, Texas. Geophys Res Lett 45:47434753. https://doi.org/10.1029/2018GL077696

Zimmerman R, Main I (2003) Hydromechanical Behavior of Fractured Rocks. In: Mechanics of fluid-saturated rocks. pp 363-421

Publisher's Note Springer Nature remains neutral with regard to jurisdictional claims in published maps and institutional affiliations. 